\title{
¿Fue la crisis política del Occidente musulmán del siglo XIII debida a un cambio climático? Una aproximación histórica al fin del Periodo Cálido Medieval
}

\author{
Was the Western Islamic Political Crisis of the $13^{\text {th }}$ Century \\ Due to climatic Change? a Historical Approach to the End of \\ the Medieval Warm Period
}

\author{
Antonio Vicente Frey SÁNCHEZ \\ Universidad de Murcia \\ tonyfrey@um.es
}

Recibido: 06/09/2015

Aceptado: 10/12/2015

\section{RESUMEN}

Durante el siglo XIII se produjo una sucesión de revueltas que supuso la desaparición del Imperio almohade y su sustitución por poderes regionales en al-Andalus, el Magreb y el Magreb al-Aqsà. La historiografía ha presentado el surgimiento y pugna entre estos poderes como un fenómeno social, político e, incluso, cultural y religioso, con el que se ha podido explicar su aniquilación o marginalización. Este trabajo pretende contextualizar los hechos desde una perspectiva medioambiental, de forma que la desintegración del califato almohade, el surgimiento de aquellos poderes y la progresión de los reinos cristianos en la península ibérica puedan entenderse desde una visión global de cambio climático y una posible crisis agrícola.

Palabras clave: Cambio climático, crisis agrícola, revueltas, Magreb, al-Andalus, Castilla.

\begin{abstract}
A succession of revolts during the $13^{\text {th }}$ century led to the end and disappearance of the Almohad Empire and its replacement by regional powers in al-Andalus, the Maghreb and Maghreb al-Aqsà. Historiography has presented the emergence and conflict between these powers as a social, political, cultural and religious phenomenon which explains the Empire's annihilation or marginalisation. The aim of this study was to contextualise these events from an environmental perspective so that the disintegration of the Almohad Caliphate, the rise of these powers and the consolidation of Hispanic Christian kingdoms can be understood from the perspective of global climate change and a possible agricultural crisis.
\end{abstract}

Key Words: Climate Change, Agricultural Crisis, Revolts, Maghreb, Al-Andalus, Castile.

Sumario: 1. Introducción. 2. Crisis política en el Occidente musulmán en el siglo XIII. Síntesis y crítica. 3. ¿Provocó la crisis climática del siglo XIII una crisis política? Exposición de hechos y su contextuali- 
zación. 3.1. Los efectos de un clima cambiante y sus implicaciones en la península ibérica y el Magreb. 3.2. Breve síntesis de las oscilaciones climáticas y carestías en Europa. 3.3. El contexto climático: el fin del Periodo Cálido Medieval. 4. Conclusiones. 5. Agradecimientos. 6. Bibliografía.

\section{INTRODUCCIÓN}

El testimonio de las fuentes árabes hace referencia a revueltas que se sucedieron en el Imperio almohade entre los años 1224 y 1244, y que acabaron con él al desintegrarse en varios estados ${ }^{1}$. Las primeras sublevaciones conocidas se iniciaron en al-Andalus, concretándose en dos poderes locales enfrentados y prendiendo, a la vez, en el Magreb con tres sultanatos focalizados en Túnez, Tremecén y Fez (fig. 1). A partir de 1244, casi liquidado el Imperio almohade, sobrevino una fase de consolidación de las nuevas entidades políticas dominada por la pugna ideológica por el reconocimiento del depósito de la legitimidad almohade; en la península ibérica esta transición tuvo mayor trascendencia, dado que concluyó con la reducción de al-Andalus a Granada².

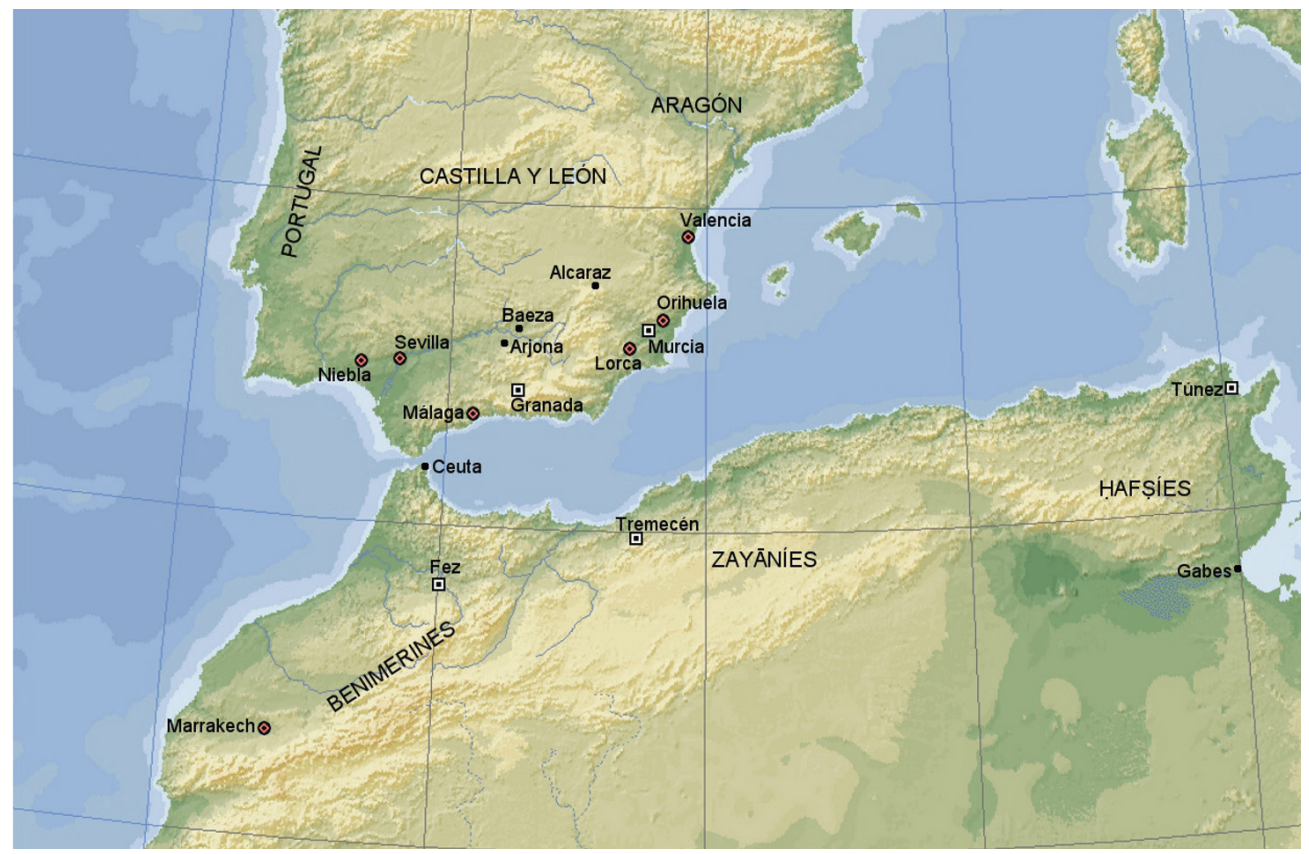

Fig. 1. Contexto geográfico.

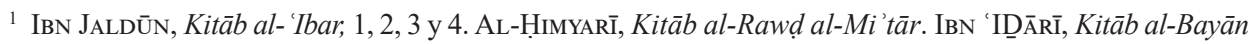
al-Mugrib, I y II. IBN ABī ZAR', Raw ḍ al-Qirțās.

${ }^{2}$ Brunschvig, La Berberie orientale. Huici miranda, Historia política del imperio almohade. De las Cagigas, Los mudéjares, II. Molina lóPez, "Murcia en el marco histórico"; "De nuevo sobre el reconocimiento público del poder político". KHANEBoubi, Les premiers sultans merinides. Viguera molins, "Historia política", VIII/2, pp. 100-123. Fierro, "Doctrinas y movimientos de tipo mesiánico", pp. 159-176. Guichard, AlAndalus frente a la conquista cristiana. Martínez EnAmorado, "Algunas reflexiones en torno al fin del almohadismo", 15-16, pp. 11-28. 
Hoy día, conocidos aquellos acontecimientos políticos, perfilado su ambiente social, económico y cultural, surge la posibilidad de preguntarse si aquel fenómeno de descomposición almohade y crisis política en al-Andalus puede contextualizarse en los cambios climáticos del Holoceno. No se trata de descartar aquellos fenómenos socio-políticos, ni proponer una versión determinista de los acontecimientos, sino complementar los hechos históricos con una perspectiva hasta ahora inédita. En rigor, existe una temprana referencia de R. Arié, quien, leyendo a al-Jațîb, se hizo eco del impacto de una sequía como posible causante del descontento de $1227 \mathrm{y}$, por lo tanto, del comienzo de las rebeliones de al-Andalus ${ }^{3}$. A su vez, existen precedentes sobre la relación entre crisis climáticas y acontecimientos históricos en otras partes del hemisferio como los asentamientos vikingos en Groenlandia y el continente americano con un retroceso de los hielos árticos en el alto medievo $0^{4}$. Su explicación radicaría en los pioneros estudios de $\mathrm{H}$. Lamb sobre la existencia de un periodo cálido medieval situado entre los siglos X y XIII, cuya crisis desembocó en un enfriamiento agudizado a partir del siglo XIV ${ }^{5}$. En un contexto de oscilación similar podría situarse -por poner ejemplos- la crisis del Imperio maya entre el 750 y el 910 D.C. ${ }^{6}$; la decadencia de la civilización de Angkor Wat ${ }^{7}$; o, las tempranas referencias de E. Le Roy con respecto a la pérdida de los cultivos vinícolas ingleses en el siglo $\mathrm{XIV}^{8}$. Aquellos estudios de H. Lamb partían de un sofisticado análisis de marcadores físico-biológicos [proxies] que posteriores investigadores han ido implementando desde los años setenta y ochenta ${ }^{9}$. Desde hace tiempo estos estudios se completan con modelos y simulaciones ${ }^{10}$, muchos de los cuales han puesto su atención en la transición climática del siglo XIII; centuria en la que se han documentado violentos eventos eruptivos ${ }^{11}$. Por su parte, en España estos estudios se están basando desde los años noventa en el empleo de datos provenientes de fuentes escritas con los que se ha reconstruido el

\footnotetext{
3 ArIÉ, III, España Musulmana, p. 35.

${ }^{4}$ IngStad, "The Excavation of a Norse Settlement". FAgan, La pequeña Edad del Hielo. PATterson et al., "Two millennia of North Atlantic seasonality", pp. 5306-10.

5 LAmb, "The early Medieval warm epoch", pp. 13-37 y Climate, History. Alexandre, "Les variations climatiques au Moyen Âge" y Le climat en Europe au Moyen Age.

${ }^{6}$ Haug et al., "Climate and the Collapse of Maya Civilization", pp. 1731-1735. Peterson y Haug, "Climate and the Collapse of Maya Civilization", pp. 322-329.

7 FAGAN, El gran calentamiento.

${ }^{8}$ Le Roy, "Histoire et Climat", pp. 4-5.

9 Por ejemplo: Hughes y DíAz, "Was there a 'Medieval Warm Period', pp. 109-142. Bradley et al., "The climate of the last millennium", pp. 105-141 y "Climate in Medieval time", pp. 404-405. SoON y BALIUNAS, "Proxy climatic and environmental changes", pp. 89-110. Jones y MANN, "Climate over past millennia". Goosse et al., "The origin of the European "Medieval Warm Period", pp. 99-113; Goosse et al., "The role of forcing and internal dynamics", pp. 2847-2866. DíAz et al., "Spatial and temporal characteristics of climate", pp. 1487-1500.

10 Por ejemplo: Crowley et al., "Modeling ocean heat content changes", p. 1932. Mann y Jones, "Global surface temperatures". Hunt, "The Medieval Warm Period", pp. 677-694. OsBorn et al., "Simulated climate change". MANN et al., "Proxy-based reconstructions of hemispheric", pp. 13252-13257. MANN et al., "Global Signatures and Dynamical Origins", pp. 1256-60.

11 Stothers y Rampino, "Historic Volcanism, European Dry Fogs", pp. 411-413. Grove y Switsur, "Glacial Geological Evidence for the Medieval Warm Period", pp. 143-169. Rовоск, "Volcanic eruptions and climate", pp. 191-219. STотHERs, "Climatic and demographic consequences of the massive volcanic eruption of 1258", pp. 361-374. ATwell, "Volcanism and Short-Term Climatic Change”, pp. 29-98.
} 
clima histórico ${ }^{12} ; \mathrm{y}$, también, en mayor escala temporal, en este caso como estudios paleoclimáticos, con proxies devenidos de análisis sedimentológicos, dendrológicos, palinológicos, etc. que pueden sintetizarse en el trabajo del CLIVAR-España de 2010, y que serán citados a lo largo de este artículo ${ }^{13}$.

Un elemento consecuente a las alteraciones climáticas es su incidencia; incidencia que, en el marco de sociedades agrícolas encuentra un interesante punto de referencia en las alusiones documentales sobre su impacto en la productividad de la tierra, ya sea por la acción de los elementos sobre las especies cultivadas como por la capacidad del hombre de sobrellevar, en consecuencia, su ruina en una época donde existía una delgada línea entre la abundancia y la escasez; aspecto, este último, que ha sido motivo de numerosos estudios ${ }^{14}$. De hecho, todavía son muy raras las hipótesis sobre la incidencia de las grandes crisis climáticas en los reinos medievales peninsulares, aunque con cierta prudencia algunos investigadores ya han apuntado la posibilidad de relacionar episodios de baja producción agrícola en el siglo XIV con los prolegómenos de la Pequeña Edad de Hielo entre otros aspectos ${ }^{15}$. En este caso, sabiendo el fundamental papel de la productividad agrícola en el marco de la economía tributario-mercantil que caracterizaba a los estados del Islam occidenta ${ }^{16}$, este artículo va a interpretar algunas fuentes magrebíes y castellanas, a partir de sus traducciones y trascripciones, para incidir en la cuestión planteada en su momento por R. Arié, lo que, unido a informaciones sobre producción cerealista estudiados durante los últimos años, podría contextualizar un escenario de oscilación climática con consecuencias en intermitentes crisis agrícolas, crisis de subsistencia, guerras, desplazamientos de población y, finalmente, crisis políticas concretadas en revueltas urbanas y segregación de poderes más o menos exitosos ${ }^{17}$. Consciente de la relativa parquedad de las fuentes árabes, y en ausencia de abundantes marcadores físico-biológicos en el área geográfica en cuestión, este estudio se plantea como una propuesta que sintetiza

12 Por ejemplo: BARRIENDOS, "El clima de la península Ibérica a través de los registros históricos", pp. 343362; "La climatología histórica en España", pp. 15-56; "La reconstrucción del clima a partir de testimonios históricos", pp. 18-20. VAquero, "Reconstruction of Past Mediterranean Climate". VAquero et al., "Arabic Chronicles: an unexplored source for the reconstruction of past Mediterranean climate". CREUs et al., "Los estudios de paleoclimatología en España", 249-282. DomíngueZ-CASTro et al., "How useful could Arabic documentary sources be for reconstructing past climate?", pp. 76-82.

13 CACHO et al., "Revisión de las reconstrucciones paleoclimáticas", pp. 18-19.

14 Por ejemplo, Vernet; "Recherches sur la production et la circulation des céréales", pp. 31-62; "La production cerealiere dans le Maghreb", pp. 253-268. Benito i Monclús, "Fams i carestíes a la Mediterrànea occidental", pp. 179-194. MENANT, "Crisis de subsistencia y crisis agrarias en la Edad Media”, pp. 17-60. FAGAN, La pequeña Edad del Hielo; El gran calentamiento. ReGlero, "Les disettes dans le royaume de Castille", pp. 309-342.

15 Reglero, ibidem.

16 GuICHARD, Al-Andalus frente a la conquista cristiana.

${ }^{17}$ F. Menant ("Crisis de subsistencia y crisis agrarias en la Edad Media") diferencia la crisis de subsistencia -que afecta a todos por igual, al mundo rural como al urbano- de la crisis agrícola -centrada en el campo y que «afecta desde muchos puntos de vista a los habitantes de las ciudades, que pueden sufrirla o sacar provecho de ella". También, la carestía - devenida de una crisis de subsistencia- muy diferente del hambre en sentido estricto, ya que bajo tal acepción debe entenderse aquellas graves carestías "que desencadenan mortalidades importantes y también transformaciones estructurales de la economía y de la sociedad; entre ellas, la venta de tierras por parte de los campesinos para comprar alimentos». Ver, también, el epígrafe titulado "Carestia no és igual a fam” de P. Benito I Monclús, "Fams i carestíes a la Mediterrànea occidental”, pp. 180-181. 
los datos climáticos hasta ahora estudiados para relacionarlos con aquellas noticias, con el objetivo de presentar, en las conclusiones, una lectura complementaria a los cambios políticos en el siglo XIII del occidente musulmán.

\section{CRISIS POLÍTICA EN EL OCCIDENTE MUSULMÁN EN EL SIGLO XIII. SÍNTESIS Y CRÍTICA}

La lectura de fuentes muestra que la desintegración del poder almohade comenzó en al-Andalus con las sublevaciones de al-'Adil, al-Bayyāsī y Abū-l-'Ulā Idrīs b. Ya' qub, tras la muerte de los califas Yūsuf II (1224) y Abū-l- 'Ulà al-Ma'mūn (1226), con el idéntico fin de reclamar el trono almohade ${ }^{18}$. Poco después, a aquéllas le siguieron las insurrecciones de Muhammad b. Yūsuf b. Hūd en Murcia (1228) y de Abū Zakariyā' Yahyyā b. Hafṣ en Gabès (1229) y la de Yagmurāsan b. Zayyān en Tremecén (1235); produciéndose como corolario la conquista de Fez por Abū Yahyā b. 'Abd alHaqq (1244). Y aunque el califato almohade se mantuvo hasta 1268-69, cada uno de los últimos poderes citados se reivindicó como legítimo sucesor de la legalidad almohade, comenzando una pugna por el reconocimiento de su supremacía en el Islam occiden$\mathrm{tal}^{19}$.

Para el final del siglo XIII sólo tres de los poderes centrífugos habían sobrevivido: el emirato hạașí, el zayyāní y el benimerín, pues el hūdí había sido fagocitado por Castilla y Aragón en un recorrido que puede resumirse así: Sublevado Ibn Hūd, fue proclamado en Murcia, solicitando el reconocimiento público del poder político (ba ya); consciente de la necesidad de dotar al nuevo emirato de una legalidad, tras solicitarlo, consiguió el placet del califato 'abbāsíi ${ }^{20}$. Contra aquél se levantaron varios arráeces entre los que despuntó en 1232 al-Ahmar b. Nașr, quien, para marcar las distancias con el proyecto político hūdí y después de ciertos vaivenes, optó por hacerse cliente del califato almohade $^{21}$. El fracaso hūdí en aglutinar una histórica unidad andalusí contrasta -a pesar de observarse un similar proceso con un notable componente urbano- con el éxito de los norteafricanos: Sublevado Abū Zakariyā', tras su inicial proclamación en Gabès fue a Túnez donde consolidó su autoridad ${ }^{22}$. Al mismo tiempo, los zayyāníes tomaban el control de la ciudad de Tremecén, donde establecieron un emirato en $1235^{23}$. Finalmente, en el Magreb al-Aqsà los benimerines, que en 1228 habían franqueado sus posiciones

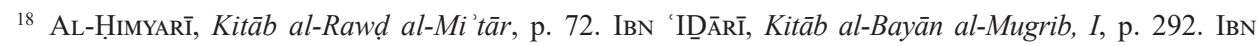
JALDŪN, Kitāb al-'Tbar, II, pp. 230 y 233-234.

${ }^{19}$ Vidal Castro, “Al-Andalus y Marruecos en la Baja Edad Media”, pp. 21-22. Martínez Enamorado, "Algunas reflexiones en torno al fin del almohadismo", pp. 11-28.

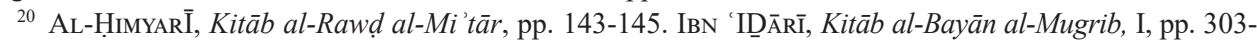
305. Primera Crónica General, p. 721.

${ }^{21}$ IBN 'ID̄̄RĪ, ibidem, pp. 320-321. IBN JALDŪn, Kitāb al-'Ibar, II, pp. 306, 312. AL-QALQAŠAnDĪ, Șubh al-A 'š $a$, p. 77.

${ }^{22}$ IBN 'ID̄ĀRĪ, ibidem, pp. 329-331. IBn JALDŪn, ibidem, pp. 297-300. IBn ABī ZAR', Raw ḍ al-Qirțās, p. 484.

${ }^{23}$ IBn Jaldūn, Kitāb al- 'Tbar, III, pp. 340-342. IBn ABī ZAR', ibidem, p. 497.
} 
del río Muluya, hicieron su entrada en Fez, haciéndola su capital y marginando al califato almohade hasta su definitiva aniquilación en las fechas referidas ${ }^{24}$.

Mientras que el Magreb progresaba en su atomización, en al-Andalus las luchas intestinas - muy relacionadas con la presión de los reinos feudales- conllevaron la aniquilación de todos los poderes constituidos entre 1228 y 1232, sobreviviendo únicamente al-Aḥmar, quien se atrincheró en Granada, fundando una dinastía -la nazarí- que perduró hasta $1492^{25}$. Con ese contexto, la historiografía ha llamado la atención sobre el desigual éxito de cada uno de aquellos poderes, tratando de explicarlo de muchas maneras, pero reivindicando un denominador común: la desesperación por poder gestionar una crisis en que la supervivencia era el último recurso. En ese panorama la característica común de casi todos ellos fue el protagonismo de las revueltas urbanas que, al menos en al-Andalus, supuso uno de sus últimos fenómenos sociopolíticos antes de su reducción a Granada ${ }^{26}$.

A la hora de estudiar aquel fenómeno -salvo casos muy excepcionales que han tratado de delimitar el papel de los habitantes de las ciudades-, dado que ha prevalecido una óptica donde el ambiente cultural o ideológico tenía una significativa importancia, se ha prestado una moderada atención a sus condiciones materiales; más aún cuando se ha constatado a través de la arqueología y diversas fuentes escritas el vínculo entre las revueltas urbanas y las circunstancias relacionadas con el bienestar de sus habitantes, al menos en la ciudad de Murcia, capital del emirato hūdíi ${ }^{27}$. En efecto, ha habido ocasión de plantear una interacción entre las condiciones de las ciudades, su campo circundante y sus pobladores durante las numerosas sublevaciones, revelando una implicación e interrelación de los diferentes estamentos de la sociedad andalusí para provocar las revueltas descritas. Ello a partir del desconcierto ante el avance castellano-aragonés, que fue un importante acicate meridianamente recogido en las fuentes de la época con sintomáticas expresiones del estilo "ençerro los alaraues con la su uenida"28, que explicitaba claramente que el panorama bélico había movido a la población a buscar refugio, provocando una presión demográfica en las ciudades; fenómeno que se podía demostrar gracias a la arqueología, debido a un notable crecimiento en la densidad por habitante, reflejado en viviendas más fragmentadas, y crecimientos en altura ${ }^{29}$. En ese contexto los medios materiales con que contaron los poderes fugaces para reivindicarse y consolidarse cobraban una singular importancia, por lo que, en el seno de una sociedad de fuerte componente agrícola como la del siglo XIII, era evidente que esos medios debían tener su origen fundamentalmente en la tierra -en el caso de Murcia,

${ }^{24}$ IBn JALDŪn, Kitāb al- 'Ibar, IV, pp. 25 y ss. IBn ABī ZAR', ibidem, pp. 484; 503-508 y 579-582.

${ }^{25}$ Otros poderes locales surgidos entre 1228 y 1239, y luego aniquilados, fueron el de Zayyān b. Mardanīš en Onda-Valencia (1229); Ibn Zannūn en Málaga y al-Bāŷ̄ en Sevilla (1232); Ibn Mậūz en Niebla (1234); 'Azīz b. Jațtab en Murcia (1238); Ibn 'Ișam en Orihuela y 'Alī b. Aḥla en Lorca (1239).

26 DE las Cagigas, Los mudéjares, II, pp. 331-338; Sevilla almohade, pp. 23-33. Molina LóPEZ, “Aziz b. Jattab", pp. 63-86; "El Levante y Almería en el marco de la política interior”, pp. 55-63; "Murcia en el marco histórico", pp. 187-263; "De nuevo sobre el reconocimiento público del poder político", pp. 793-812. GuICHARD, Al-Andalus frente a la conquista cristiana, pp. 165-202.

${ }^{27}$ Manzano Martínez, "Notas sobre demografía islámica en Murcia”, pp. 117-181. Frey SÁnchez, "La estructura de la propiedad de la tierra en Murcia", pp. 49-76 y "Ciudades y poder político en al-Andalus", pp. 845-885.

28 Primera Crónica General, p. 679.

${ }^{29}$ Frey SÁnchez, "Ciudades y poder político en al-Andalus”, pp. 845-885. 
capital hūdí, sobre todo en su huerta-, lo cual incrementaba la importancia de su producción como de su productividad final concretada en rentas e impuestos, porque de ella dependía, por un lado, el sustento de los habitantes de las ciudades como, por otro lado, los recursos del incipiente majzan de cada uno de esos podere ${ }^{30}$ para lanzarse a operaciones políticas o, en última instancia, mantener un status quo. En ese caso, como J. Manzano demostró, hacia mitad del siglo XIII su campo y su huerta presentaban un alto índice de minifundismo -el 50\% de las propiedades eran menores a 3 tahúllas- y, también, concentraciones de propiedad en alquerías -el 15\% de propietarios tenía el $50 \%$ de las tierras- donde el común tribal se había debilitado hasta llegar a proporciones únicamente del 2 ó 3\% de sus rentas ${ }^{31}$. Con esas cifras, no hace falta mucha imaginación para deducir qué debía ocurrir en ciudades atestadas de refugiados, ubicados precariamente y dependientes de otros para su alimentación. Ello conduce inevitablemente a considerar que, aunque era evidente que la batalla de Las Navas de Tolosa representó un punto de inflexión en el dominio almohade en al-Andalus ${ }^{32}$, no bastaba para explicar el detonante de aquel proceso de aparición de poderes fugaces, sino que se apreciaba una esclarecedora coincidencia entre los primeros alzamientos anti-almohades y las noticias de sequías, carestías, hambrunas y enfermedades durante el primer tercio del siglo XIII en general, y entre 1227 y 1228 en particular.

\section{3. ¿PROVOCÓ LA CRISIS CLIMÁTICA DEL SIGLO XIII UNA CRISIS POLÍTICA? EXPOSICIÓN DE HECHOS Y SU CONTEXTUALIZACIÓN}

Advertir el alcance de una carestía y una hambruna en los territorios andalusíes, a sabiendas por aproximación de cuál era la productividad de la tierra a través de los posteriores libros de repartimiento resulta con todo difícil, pues únicamente se cuenta con los testimonios de sus crónicas, cuyas noticias relataban significativos acontecimientos regionales y raramente locales. También puede contarse con las castellanas y aragonesas; de hecho, gracias a pequeños detalles de ellas se puede pensar en un comercio de grano intermitente y constantemente interrumpido por la guerra; otras hablan directamente de saqueos y talas masivas, lo que sin duda provocarían también sus debidas carestías y hambrunas. Pero todo ello resulta a todas luces insuficiente en muchos casos si no se consideran los acontecimientos meteorológicos provocados por una aparente oscilación climática, tal y como algunos proxies indican respecto a temperaturas y precipitaciones $^{33}$, y sus efectos tanto en la producción para la alimentación como para el almacenamiento de grano para subsiguientes cosechas a corto plazo. En ese sentido, los cambios en el uso de la tierra en la Península durante ese siglo serían otros indicadores fiables de la acción del hombre y el clima oscilante ${ }^{34}$.

${ }^{30}$ GUICHARD, Al-Andalus frente a la conquista cristiana, pp. 387-389.

31 Manzano Martínez, “Aproximación a la estructura de la propiedad”, pp. 61-75. Frey SÁnChez, "La estructura de la propiedad de la tierra en Murcia”, pp. 49-76.

${ }^{32}$ Huici Miranda, Historia política del imperio almohade, I, pp. 382-383.

33 Manrique y Fernández-CANCio, "Extreme climatic events in dendroclimatic”, pp. 123-138.

34 Por ejemplo, López SÁEz et al., "Historia de la vegetación en el litoral”, pp. 13-28. López SÁEz et al., "Contribución paleoambiental al estudio de la trashumancia”, pp. 24-30. Morellón et al., "Evolución sedimentaria y geoquímica del Lago de Estanyña”, pp. 115-118. 


\begin{tabular}{|l|c|c|c|c|c|}
\hline & Europa & Castilla y León & Aragón & al-Andalus & Magreb* \\
\hline $\mathbf{1 2 0 7}$ & & $\mathrm{HE}, \mathrm{I}$ & & & \\
\hline
\end{tabular}

\begin{tabular}{|c|c|c|c|c|c|}
\hline 1213 & $\mathrm{~S}, \mathrm{HE}$ & $\mathrm{c}, \mathrm{h}, \mathrm{e}$ & $\mathrm{c}, \mathrm{h}, \mathrm{e}$ & \multicolumn{2}{|c|}{$\mathrm{c}, \mathrm{h}, \mathrm{e}$} \\
\hline 1214 & HE, S & $\mathrm{c}, \mathrm{h}, \mathrm{e}$ & $\mathrm{c}, \mathrm{h}, \mathrm{e}$ & \multicolumn{2}{|c|}{$\mathrm{c}, \mathrm{h}, \mathrm{e}$} \\
\hline 1215 & \multicolumn{2}{|c|}{$\mathrm{L}$} & & & \\
\hline 1216 & \multicolumn{2}{|c|}{$\mathrm{L}$} & & & \\
\hline 1217 & \multicolumn{2}{|c|}{$\mathrm{L}$} & & & \\
\hline 1218 & & & & \multicolumn{2}{|c|}{$S$} \\
\hline 1219 & & & & \multicolumn{2}{|c|}{$\mathrm{S}$} \\
\hline 1220 & & & & $\mathrm{~S}$ & $\mathrm{c}$ \\
\hline 1221 & & & & $\mathrm{~S}$ & $\mathrm{c}$ \\
\hline
\end{tabular}

\begin{tabular}{|c|c|c|c|c|c|c|}
\hline \multicolumn{7}{|c|}{$(\ldots)$} \\
\hline 1224 & $\mathrm{mc}, \mathrm{c}$ & c & & & & \\
\hline 1225 & $\mathrm{mc}, \mathrm{c}$ & $\mathrm{c}$ & & & & \\
\hline 1226 & $\mathrm{mc}, \mathrm{c}$ & $\mathrm{c}$ & & & & \\
\hline 1227 & $\mathrm{mc}, \mathrm{c}$ & & $\mathrm{S}$ & $\mathrm{c}$ & & \\
\hline 1228 & $\mathrm{c}$ & & & & $\mathrm{S}$ & $\mathrm{c}, \mathrm{h}$ \\
\hline
\end{tabular}

\begin{tabular}{|c|c|c|c|c|c|c|c|}
\hline \multicolumn{8}{|c|}{$(\ldots)$} \\
\hline 1232 & & & & $\mathrm{~S}$ & $\mathrm{~S}$ & \multicolumn{2}{|c|}{$\mathrm{c}, \mathrm{h}, \mathrm{e}$} \\
\hline 1233 & HE, L & $\mathrm{c}$ & $\mathrm{HE}$ & & $\mathrm{HE}$ & $\mathrm{HE}$ & $\mathrm{c}, \mathrm{h}, \mathrm{e}$ \\
\hline 1234 & $\mathrm{HE}$ & $\mathrm{c}$ & $\mathrm{HE}$ & & $\mathrm{HE}$ & & \\
\hline 1235 & & & & & $\mathrm{c}$ & & \\
\hline 1236 & $\mathrm{~L}$, & & & & & & \\
\hline 1237 & & & & & $\mathrm{c}, \mathrm{e}$ & & \\
\hline 1238 & $\mathrm{~S}$, & & & & $\mathrm{c}, \mathrm{h}, \mathrm{e}$ & & \\
\hline 1239 & & & & & $\mathrm{~L}$ & $\mathrm{~L}$ & $\mathrm{e}$ \\
\hline
\end{tabular}

\begin{tabular}{|l|c|c|l|l|l|}
\hline 1256 & $\mathrm{~L}$ & $\mathrm{mc}, \mathrm{c}$ & $\mathrm{c}, \mathrm{h}$ & & \\
\hline 1257 & $\mathrm{c}, \mathrm{e}$ & $\mathrm{c}, \mathrm{h}$ & & & \\
\hline 1258 & $\mathrm{c}$ & $\mathrm{c}, \mathrm{h}$ & & & \\
\hline 1259 & $\mathrm{c}$ & $\mathrm{c}, \mathrm{h}$ & & & \\
\hline 1260 & & $\mathrm{c}, \mathrm{h}$ & & & \\
\hline 1261 & & $\mathrm{c}, \mathrm{h}$ & & & \\
\hline 1262 & & $\mathrm{c}, \mathrm{h}$ & & & \\
\hline 1263 & & $\mathrm{c}, \mathrm{h}$ & & & \\
\hline 1264 & & $\mathrm{c}$ & & $\mathrm{c}$ & \\
\hline 1265 & & $\mathrm{c}$ & & $\mathrm{c}$ & \\
\hline 1266 & & $\mathrm{c}$ & & & $\mathrm{c}$ \\
\hline 1267 & & $\mathrm{c}$ & & & \\
\hline 1268 & & $\mathrm{c}$ & & & \\
\hline
\end{tabular}

Tabla 1. Síntesis de fenómenos meteorológicos e incidencias detectadas en las fuentes escritas. Clave: (S): Sequía; (L): Lluvia; (HE): Helada; (I): Inundaciones / (mc): Malas Cosechas; (c):

Carestía; (h): Hambre; (e): Enfermedad.

*Incluye Magreb y Magreb al-Aqsà (actual Marruecos). 
Para conseguir el objetivo propuesto en este trabajo se han analizado datos de las fuentes árabes Kitāb al-Rawd al-Mi'tār de al-Himyarī, Kitāb al-Bayān al-Mugrib de Ibn 'Id̄āin, Raw d al-Qirțās de Ibn Abī Zar' y extractos de testimonios del Kitāb Zawāhir al-Fikar de al-Murābit; al igual que de las fuentes castellanas Anales Toledanos y Primera Crónica General. También se han incorporado referencias documentadas por otros historiadores a los que aludiré a lo largo de la exposición. Gracias a todas ellas, como puede apreciarse en la tabla 1, se han documentado treinta y nueve referencias a carestías; veinte a hambrunas; trece a epidemias; once a sequías; cinco a grandes precipitaciones; una a inundaciones; y seis a heladas en un periodo que va de 1207 a 1268 . Por si hubiera alguna duda de la estacionalidad del conjunto de los acontecimientos en torno a esa horquilla cronológica, un rápido estudio estadístico del Rawd al-Qirțās, cuyos contenidos ocupan desde el año 788 hasta 1326, sitúa el periodo 1207-1268 por detrás del comprendido entre 919 y 1020 -años centrales del Periodo Cálido Medieval- cuando se llegaron a documentar en el Magreb y al-Andalus hasta dieciocho acontecimientos relacionados con el clima y la meteorología ${ }^{35}$.

\subsection{LOS EFECTOS DE UN CLIMA CAMBIANTE Y SUS IMPLICACIONES EN LA PENÍNSULA IBÉRICA Y EL MAGREB}

La lectura de los Anales Toledanos ${ }^{36}$ indica que en 1207 se produjeron importantes inundaciones y heladas en Castilla que fueron preludio del duro bienio climático 1213-14 que relata aquella fuente y la Primera Crónica General. Estos dos años suponen un claro testimonio de los graves efectos de una oscilación climática a la baja sobre el campo y las personas. Su incidencia comprendió tanto a la península ibérica como al Magreb, es decir un área geográfica que hoy día abarca las fachadas climáticas atlántica-continental y mediterránea de la clasificación de Köppen-Geiger ${ }^{37}$. El Raw d al-Qirțās, texto que relata los más significativos episodios de carestía y subsiguiente hambruna producida por aquéllos, refiere el citado bienio con que "hubo una gran peste asoladora en al-Magrib y en al-Andalus"38; y lo que no deja dudas sobre el origen de aquella situación se lee en al-Bayān al-Mugrib: "una gran esterilidad [de la tierra] y hambre (...) sufrieron los nómadas y los sedentarios y llegó la situación por el exceso de precios a no tener fin"39. Esa descripción representa una pauta que el conjunto de los testimonios escritos permite advertir que fue común en muchos casos (tabla 2): previa a la enfermedad, hubo de producirse un episodio de producción agrícola insuficiente para el conjunto de un territorio y, por ello, la subsiguiente hambruna que reducía el umbral inmunológico de los hombres; por lo que, además de producirse la expansión de las enfermedades, el pueblo debía enfrentarse a un alza de precios. Más aún, en ese escenario de oscilación climática a la baja, que fue común a lo largo de la primera mitad del siglo, hay que tener presente el impacto

\footnotetext{
35 Recogidos en otro trabajo mío: Frey SÁNCHEZ, "El origen y expansión almorávide”, pp. 225-253.

36 Anales Toledanos, p. 177.

37 Kоттек et al., "World Map of the Köppen-Geiger", pp. 259-263.

38 IBN AB⿳亠丷厂 ZAR', Raw d al-Qirțās, p. 523.

39 IBN 'ID̄̄̄ī̄, Kitāb al-Bayān al-Mugrib, I, p. 279.
} 
de las acciones bélicas en la Península o las insurrecciones armadas en el Magreb, lo que redundaría, a su vez, en aquella producción de alimentos. El corolario de esa situación sería el desplazamiento para la búsqueda de sustento:

En este año [de 1213] fi elada en October, e en November, e Janero, e Febrer, e non lovio en Marcio, en Abril, ni en Mayo, ni en Junio, o nunca tan mal anno fue, o non cogiemos pa ninguno, e fugieron los quinteros e ermaronse las Aldeas de Toledo ${ }^{40}$.

\begin{tabular}{|c|c|c|c|}
\hline Año(s) & Fuente & Texto (páginas) & Episodios políticos \\
\hline \multirow[b]{2}{*}{$1213-14$} & Rawḍ al-Qirțās & $\begin{array}{l}\text { “... hubo una gran peste asoladora en al- } \\
\text { Magrib y en al-Andalus" (523) }\end{array}$ & \\
\hline & Bayān al-Mugrib & $\begin{array}{l}\text { "Se produjo una gran esterilidad y } \\
\text { hambre que sufrieron los nómadas y los } \\
\text { sedentarios y llegó la situación por el } \\
\text { exceso de precios a no tener fin" (289) }\end{array}$ & \\
\hline 1218-19 & Bayān al-Mugrib & [Sequía] (293) & \\
\hline $1220-21$ & Raw ḍ al-Qirțās & $\begin{array}{l}\text { “... hubo en al-Magrib gran carestía, } \\
\text { sequía y plaga de langostas" (523) }\end{array}$ & \\
\hline \multirow[t]{2}{*}{$1226-27$} & \multirow[t]{2}{*}{ Rawḍ al-Qirțās } & $\begin{array}{l}\text { "Al mes de gobernar Yahyà en Marrākush } \\
\text { se sublevó contra él el país, los precios } \\
\text { se encarecieron, los caminos fueron } \\
\text { infestados y se enseñorearon la ruina y la } \\
\text { desolación en el Magrib con las continuas } \\
\text { revueltas" (482) }\end{array}$ & \multirow{2}{*}{$\begin{array}{l}\text { Sublevaciones de al-'Adil, al-Bayyāsī y } \\
\text { Abū-l-'Ulā Idrīs b. Ya'qub tras la muerte } \\
\text { del califa Yūsuf II (1224) } \\
\text { Sublevación de Abū-l- 'Ulà al-Ma'mūn } \\
\text { (1226) }\end{array}$} \\
\hline & & $\begin{array}{l}\text { "... hubo carestia en al-Magrib y en al- } \\
\text { Andalus; el cahiz de trigo se vendió a } \\
\text { quince dinares; hubo trerrible plaga de } \\
\text { langosta en al-Magrib" (525) }\end{array}$ & \\
\hline \multirow[t]{4}{*}{1228} & \multirow[t]{4}{*}{ Rawḍ al-Qirțās } & \multirow{4}{*}{$\begin{array}{l}\text { “Cuando Abū-l-'Alā b. al-Mansūr acude } \\
\text { al trono (...) se abrasó el país en revueltas } \\
\text { contínuas, devastaciones, sequías, terribles } \\
\text { carestías e inseguridad en los caminos. Se } \\
\text { echó el enemigo sobre la mayor parte de } \\
\text { los países musulmanes en al-Andalus; los } \\
\text { banū Hafs se hicieron independientes en } \\
\text { Ifrīqiya. Los Benimerines penetraron en } \\
\text { al-Magrib” (484) }\end{array}$} & $\begin{array}{l}\text { Entrada de los benimerines en Magreb } \\
\text { al-Aqsà desde sus posiciones del río } \\
\text { Muluya } \\
\text { Insurrección de Muhammad b. Yūsuf b. } \\
\text { Hūd en Murcia (1228) }\end{array}$ \\
\hline & & & $\begin{array}{l}\text { Insurrección de Abū Zakariyā' Yahyā b. } \\
\text { Hafș en Túnez (1229) }\end{array}$ \\
\hline & & & Pérdida de Cáceres (1229) \\
\hline & & & Pérdida de Mérida y Badajoz (1230) \\
\hline \multirow{3}{*}{$1232-33$} & \multirow{3}{*}{ Rawḍ al-Qirțās } & \multirow{3}{*}{$\begin{array}{l}\text { "Al-Magrib se despobló y hubo en él gran } \\
\text { peste y hambre; el cahiz llegó a valer } 80 \\
\text { dinares" (527) }\end{array}$} & $\begin{array}{l}\text { Insurrección de al-Ahmar b. Naṣr en } \\
\text { Arjona (1232) }\end{array}$ \\
\hline & & & $\begin{array}{l}\text { Insurrección de Ibn Mạ̣fūz en Niebla } \\
\text { (1234) }\end{array}$ \\
\hline & & & $\begin{array}{l}\text { Insurrección de Yagmurāsan b. Zayyān } \\
\text { en Tremecén (1235) }\end{array}$ \\
\hline
\end{tabular}

${ }^{40}$ Anales Toledanos, p. 177. 


\begin{tabular}{|c|c|c|c|}
\hline \multirow{2}{*}{$1237-38$} & \multirow{2}{*}{ Rawḍ al-Qirțās } & $\begin{array}{l}\text { "Por ese tiempo hubo en al-Andalus y en } \\
\text { al-Magrib una terrible carestía y una peste } \\
\text { gravisima, que desoló muchas provincias; } \\
\text { llegó entonces a valer el cahiz de trigo } \\
\text { ochenta dinares" (496) }\end{array}$ & \multirow{3}{*}{$\begin{array}{l}\text { Pérdida de Valencia (1237) } \\
\text { Caída de Muhammad b. Yūsuf b. Hūd } \\
(1238)\end{array}$} \\
\hline & & $\begin{array}{l}\text { "... la carestía y la peste se cebaron de } \\
\text { tal modo en al-Magrib que los hombres } \\
\text { se comian unos a otros y se enterraba en } \\
\text { una sola fosa un centenar de hombres" } \\
(529)\end{array}$ & \\
\hline 1238 & Kitāb Zawāhir & $\begin{array}{l}\text { "El hambre es general en todas partes y } \\
\text { la pobreza no conoce unos límites como } \\
\text { éstos. Ni cebada ni trigo. En cuanto al pan } \\
\text { amasado, eso no tiene nombre" (61) }\end{array}$ & \\
\hline 1239 & Bayān al-Mugrib & $\begin{array}{l}\text { [Abundancia de lluvias y subsiguientes } \\
\text { epidemia en Marrakech. Carestía y } \\
\text { hambre en Ceuta] (203) }\end{array}$ & $\begin{array}{l}\text { Desintegración de al-Andalus } \\
\text { 1248) }\end{array}$ \\
\hline $1264-65$ & Bayān al-Mugrib & $\begin{array}{l}\text { [Gran carestía. Adquisición difícil de } \\
\text { alimentos] (294) }\end{array}$ & $\begin{array}{l}\text { Sublevación mudéjar (1264-1266) } \\
\begin{array}{l}\text { Aniquilación del califato almohade } \\
(1268-69)\end{array}\end{array}$ \\
\hline
\end{tabular}

Tabla 2. De incidencias climáticas, epidemiológicas y agrícolas según las fuentes árabes.

¿En qué consistió la oscilación climática a la baja? La crisis del bienio 1213-14, como puede leerse en aquella cita, se caracterizó en Castilla por unas temperaturas inusualmente bajas en otoño-invierno de 1213-14 y una primavera extremadamente seca, lo que arruinó las ya menguadas cosechas del año anterior. Como resultado se registró un hambre tan dramática como la del Magreb, como la misma fuente indica: "Fasta el Verano [de 1214], e murieron lo mas de las gientes; e comieron las bestias, e los perros, e los gatos, e los mozos que podian furtar" 4 . Tal fue su impacto, que la Primera Crónica General alude a sus efectos coincidentes con la conquista de Alcaraz:

“Esse anno [de 1213] (...) fallesçieron las viandas por tod el regno de Castiella que querien los omnes pan et auienlo muy mester et non fallauan quien lo ouiesse que ge lo diesse, et muriensse de fambre los omnes por las plaças et por las carreras (...) pero tanta era la mingua en el fructo de la tierra et ell corrompimiento dell aer, que aun en las aues et en las greyes de las oueias et en los bustos de las vacas que se fazen por engendramiento, dize la estoria que en aquell anno nin se enprennaron nin parieron por mingua de çeuada et de paia et de pastos" $"$.

Lo que supuso, además, detener el avance conquistador:

"Et assi cresçio alli la fambre, que la hueste con premia de la mingua de la ujianda ouieron a comer carne en los dias que non deuien nin lo solien fazer segund nuestra ley (...) et el rey don Alffonso de Castiella, allongandose la çerca de Baesça -y non acorrien viandas de la tierra- aquexada de la fambre ya la hueste et desfalleçiendo ya todos, torno por consseio de los suyos las treguas de cabo a los moros, et uenos-

41 Idem, p. 224.

42 Primera Crónica General, p. 706. 
se entonçes pora Calatraua con su hueste. Et los freyles, et los otros omnes que en Calatrauan morauan, estauan lazrados de fambre et de mesquindad de mala guisa" $"$.

E, incluso, podría relacionarse con la muerte del rey castellano Alfonso VIII víctima de unas fiebres en 1214, y, por extensión, el inicio de una conflictiva regencia que paralizaría más aún la expansión castellana.

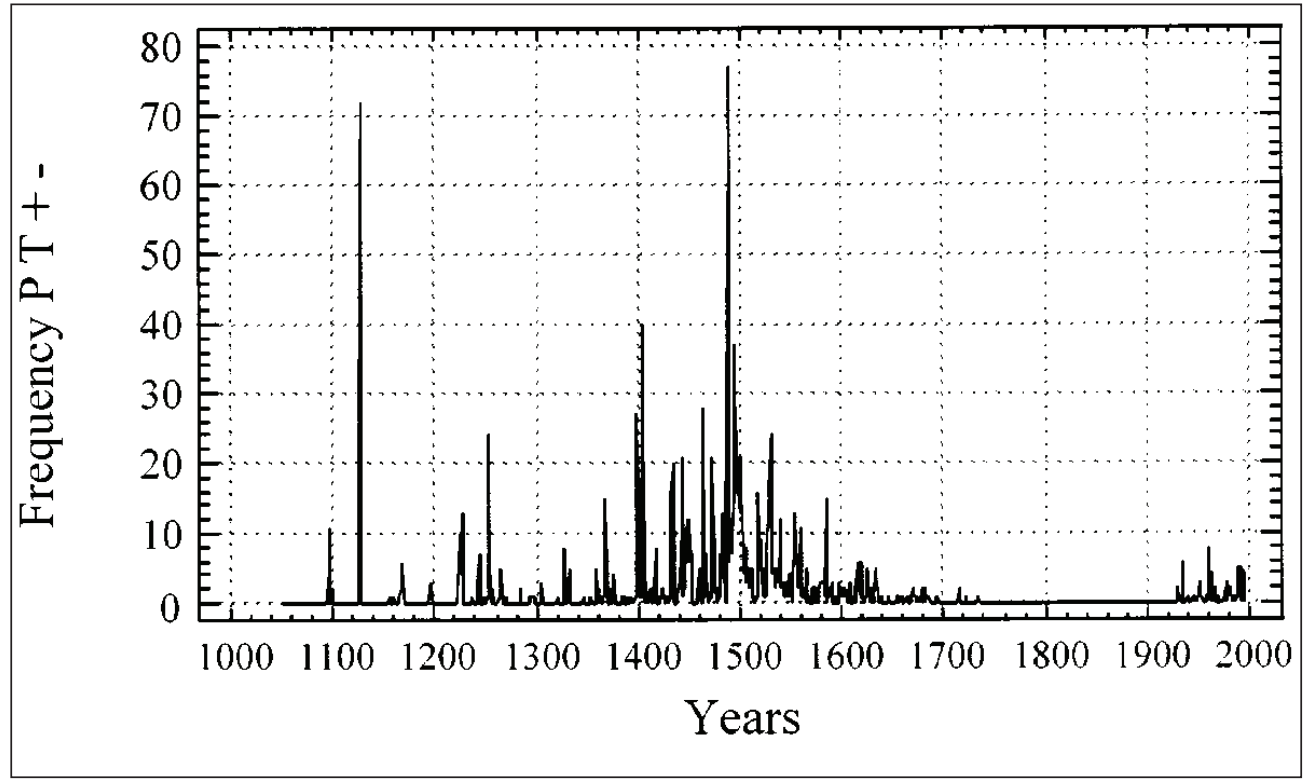

Fig. 2. Frecuencia de valores fuera de rango en precipitaciones y temperaturas en diecisiete estaciones de España. La intensidad de los registros del intervalo 1200-1300 no volverán a manifestarse hasta la Pequeña Edad de Hielo (de MariQue y Fernández-Cancio, "Extreme climatic events in dendroclimatic reconstructions from Spain”, fig. 4, p. 133).

Los datos que inducen a considerar la progresiva volatilidad climática en el siglo XIII se advierten en la documentación administrativa y contable referida a la producción agrícola ${ }^{44}, \mathrm{y}$, en líneas generales, presenta una tendencia análoga a la advertida en la síntesis dendroclimática de E. Marique y A. Fernández-Cancio ${ }^{45}$, que reproduzco en el cuadro de medias de la figura 2. Gracias a la documentación, se sabe que a aquel bienio de helada y sequía le sucedió el trienio 1215-17, que se caracterizó por unas intensas precipitaciones en Castilla y en León. Se desconoce si ese régimen de precipitaciones también afectó a al-Andalus, pero, por contra, hay constancia de

\footnotetext{
${ }^{43}$ Idem, pp. 706-707.

44 Rodríguez, "Foyse da terra no ano das chuvias", pp. 199-219. ReGlero, "Les disettes dans le royaume de Castille", pp 87-143.

45 Manrique y Fernández-CANCIO, "Extreme climatic events in dendroclimatic", pp. 123-138, sobre todo figuras 4,5 y 6 .
} 
episodios recurrentes de sequía en el Magreb entre 1218-1946 que el Rawd al-Qirțās prolonga hasta el año $1221^{47}$.

Además de su alternación, otra cuestión es el desigual impacto regional de la oscilación climática y sus consecuencias, como puede apreciarse tanto en estudios palinológicos ${ }^{48}$ como en los de las crisis alimentarias ${ }^{49}$. Esto puede advertirse más claramente en el siguiente episodio climático descrito en las fuentes, el del 1224-28, que afectó a la fachada mediterránea, pues las principales referencias se encuentran en al-Andalus, el Magreb y, sobre todo, la Corona de Aragón $^{50}$. Estas últimas aluden a carestías extremas en el bienio 1224-26 que pueden ser relacionadas con la falta de grano en el Magreb, tal y como indirectamente se deduce de los efectos del tráfico comercial aragonés ${ }^{51}$. Pero fue en los territorios musulmanes donde mayor impacto tuvo la crisis agrícola en un proceso muy similar a 1213-1452: sequías; plagas; carestías; alzas de precios; desplazamientos de individuos; inseguridad; y, sobre todo, revueltas. Aunque la casuística obligaría a acudir ciudad por ciudad y territorio por territorio para contrastar las noticias de revueltas, corrientes de opinión y práctica de la $b a$ ' ya-como, por ejemplo, las que da con detalle Ibn 'Idāāī-, si se observan las referencias recopiladas en la tabla 2 puede considerarse la relación de la oscilación climática 1224-28 con las crisis políticas de al-Andalus y el Magreb descritas en el epígrafe 2 y adelantadas en su momento por R. Arié. En ese sentido, la recurrencia de la sequía y sus efectos durante los años siguientes (1232-33, 1237-38) también pueden ayudar a entender el fracaso hūdí en un contexto desastroso, tal y como atestigua una fuente contemporánea al segundo bienio: "El hambre es general en todas partes y la pobreza no conoce unos límites como éstos. Ni cebada ni trigo. En cuanto al pan amasado, eso no tiene nombre"53. El primero, el de 1232-33 es otro ejemplo de desigualdad regional más extremo aún en la oscilación del clima, pues se sabe que fue seco en el Mediterráneo occidental y muy húmedo -sobre todo el año 1233- en el resto de Europa; incluso las temperaturas llegaron a extremos, pues en el invierno de 1233 llegó a helar abundantemente tanto en el Magreb y al-Andalus como en Castilla y León. También lo hizo en el invierno de 1234 con la consiguiente afección a la disponibilidad de grano para las siguientes cosechas, ya que constan referencias a ca-

46 IBN 'IDĀēī, Kitāb al-Bayān al-Mugrib, I, p. 293.

47 IBN ABī ZAR', Rawọ al-Qirțās, p. 523.

48 PÉREz SANZ et al., "Clima y actividades humanas en la dinámica de la vegetación”, pp. 17-38.

49 Benito et al. "Magnitude and frequency of flooding in the Tagus Basin", pp. 171-192.

50 RiERa Melis, "Els pròdroms de les crisis agràries de la Baixa Edat Mitjana", pp. 35-73; "El mercado de los cereales en la corona catalanoaragonesa", pp. 87-143. BENITO I MONCLús, "Et hoc facimus propter necessitatem famis...", pp. 39-62. Furió, "Disettes et famines en temps de croissance”, pp. 343-416.

51 DufourcQ, L'expansió catalana a la Medieterrània Occidental. Interesa la síntesis de P. BENITO I MONCLÚS "Fams i carestíes a la Mediterrànea occidental”, p. 184: “... al segle XIII les crisis agràries o caresties no provocaren fams generals, sinó dificultats locals. La producció de blat era suficient per a subvenir, en periodes normals, a les necessitats de la població dels territoris que conformaven la Corona d'Aragó. Les adversitats meteorolòiques podien provocar de manera sobtada caresties, fams $i$ mortalitats, però podien ésser, i foren en nombroses ocasions, conjurades per la intervenció dels poders públics $i$, sobretot, per la integració i la intensificació del comerç".

52 IBN AB⿳亠 ZAR', Raw d al-Qirțās, p. 484.

53 Abū-l- 'Alā' Muhammad b. al-Murābiț, refiriéndose a 1238, último año de su emirato, apud MolinA LÓPEZ, "El Levante y Almería en el marco de la política interior", p. 60. 
restías y subsiguientes altos precios en Córdoba en vísperas de su conquista, en 1235, justo cuando se documenta la sublevación de Yagmurāsan b. Zayyān en Tremecén. En fin, cuatro años después, en 1239, se sabe del viaje de una delegación sevillana y ceutí a Marrakech en medio de un panorama de abundante lluvia -después de varios años de sequía- que había reducido las cosechas, viciado el aire y provocado una epidemia $^{54}$. En todo caso, que la situación fuera tan extrema en 1238-39 puede ayudar a comprender, pues, no sólo la continua sucesión de crisis políticas en las ciudades de al-Andalus sino, también, el inmediato avance castellano-leonés durante los diez años siguientes ${ }^{55}$.

Avanzado el siglo, la decrepitud de Fernando III, la entronización de Alfonso X y la necesidad de administrar las ciudades y territorios conquistados explican el alto de finales de los cuarenta; años de los que no hay constancia de problemas meteorológicos y carestías en Castilla y León, Aragón, Granada o el Magreb. Sin embargo desde 1257 sí se advierte un endurecimiento de la política colonial del rey castellano sobre los mudéjares ${ }^{56}$, y ese giro - desde el punto de vista que se enfoca este artículotiene su correspondencia con el inicio en 1256 de lo que las fuentes denominan "años malos" caracterizados por una "mengua de víveres"; algo que también se advierte en los cuadros de incidencias dendroclimáticas del citado trabajo de E. Marique y A. Fernández-Cancio ${ }^{57}$. Un estudio sobre la depresión agraria de $1255-62^{58}$ ha apuntado a 1258 como pésimo, y, señalando el bienio 1262-63 aludía a la misma fuente al indicar que los obispos replicaban a las peticiones dinerarias del papado, alegando "El terrible hambre que durante siete años había asolado el reino de Castilla"; situación que parece que se prolongó hasta 1267-68, pues con respecto a esos años la documentación del obispado de Cuenca y las actas de las Cortes de Jerez aluden a una gran carestía ${ }^{59}$. Nótese que entre los dos últimos bienios citados se produjo la sublevación mudéjar, lo que da a entender que los problemas se extendieron al Sur, como puede leerse en una esclarecedora referencia sobre una carestía donde la adquisición de alimentos era difícil ${ }^{60}$. Por su parte, no se sabe hasta qué extremo el causante de esa carestía afectó a la vecina Corona de Aragón, aunque parece ser que el conjunto de sus habitantes no sufrió hambruna generalizada alguna. Esto se infiere del desarrollo urbano registrado, por ejemplo, en los proxies sedimentarios del puerto

${ }^{54}$ Ghouirgate, "La gestion des crises de subsistance par les souverains almohades", pp. 255-266.

${ }^{55}$ Frey sánChez, "Cuando se difundió la fama de Ibn Hūd", pp. 419-432.

${ }^{56}$ RodríGuez Llopis, "Repercusiones de la política alfonsí", pp. 192-193. Frey SÁnChez, "La estructura de la propiedad de la tierra en Murcia", p. 57.

${ }^{57}$ Manrique y FernándeZ-CANCIO, "Extreme climatic events in dendroclimatic", figura 4.

${ }^{58}$ Aguadé, "En los orígenes de una coyuntura depresiva la crisis agraria", pp. 243-270.

${ }^{59}$ Rodríguez, "Foyse da terra no ano das chuvias", pp. 204-205. Reglero, "Les disettes dans le royaume de Castille", pp. 313-315. Este último indica: "El Cronicón de Cardeña anota que en enero de 1258 hubo letanías para pedir lluvia, que luego la helada estropeó las viñas y el año fue 'malo de pan'. Ese mismo año un documento asturiano se refiere a que 'los anos foront fortes et de fames'. Indirectamente podemos relacionar con ella la prohibición decretada por los concejos del obispado de Osma y otros de Castilla para que no se sacase cereal ni otro alimento de sus términos; disposición prohibida por Alfonso X el 16 de febrero de 1259. Más imprecisa resulta la noticia de que en tiempo de obispo Pedro III de Sigüenza (1251-1258) hubo un gran hambre en la tierra" (p. 314).

${ }^{60}$ IBN 'ID̄ĀRĪ, Kitāb al-Bayān al-Mugrib, II, p. 294. 
de Barcelona ${ }^{61}$, a la política de control del comercio de grano implementada a partir de $1254-57^{62}$ y, sobre todo, a la citada relación comercial con un Magreb que estaba viviendo unos años de prosperidad documentada, al menos, en $1258^{63}$.

\subsection{BREVE SÍNTESIS DE LAS OSCILACIONES CLIMÁTICAS Y CARESTÍAS EN EUROPA}

En su momento, R. Vernet ${ }^{64}$ llamó la atención sobre las crisis agrícolas en el Occidente musulmán entre los siglos XII y XIV. El precedente provenía de la línea de trabajo abierta por G. Duby sobre economía agraria en Europa ${ }^{65}$. En líneas generales los dos estudios de R. Vernet señalaban que a partir de 1195 arrancó una secuencia de depresiones en la producción de grano en el Magreb que duró prácticamente todo el siglo XIII, poniendo énfasis en el periodo 1226-1242. Los ciclos de carestía computados comprendían los años 1195 y 1324 (tabla 3), algunos de los cuales, como los periodos 1226-1227 y 1232-1242, resultaban extremadamente interesantes relacionarlos con los episodios políticos arriba descritos. Más allá del Norte de África, la historiografía ha debatido -y debate- sobre las carestías y subsiguientes hambrunas europeas, poniendo de manifiesto, en ocasiones, su relación con episodios meteorológicos prolongados ${ }^{66}$. En ese contexto, cada vez está más aceptado que los sucesos climáticos del siglo XIII se consideran un precedente de la crisis del XIV, representando el fin de un periodo de crecimiento demográfico asociado a la expansión agraria producida a partir del siglo $\mathrm{XI}^{67}$; una crisis que incidió más allá de Europa como demostró E. Le Roy, al presentar variables amplias en la geografía ${ }^{68}$, de forma que confirmaba la tesis de $\mathrm{H}$. Lamb de un enfriamiento creciente más allá, además, de ese siglo ${ }^{69}$.

${ }^{61}$ Julià BruguÉS y Riera Mora, “Usos del sòl i activitats productives a Barcelona”, pp. 174-175.

62 Laliena Corbera, "Licencias para la exportación de cereal de Aragón y Cataluña”, p. 446.

63 La cita es necesaria: "El año en que subió al poder el emir de los musulmanes Abū Yūsuf, concedió Dios a los magribies sus bendiciones y derramó sobre ellos sus bienes y la gente gozó de una abundancia y de una felicidad que nadie puede describir ni agradecer; se vendía entonces la harina en Fez y otras ciudades de al-Magrib [...] y el trigo [...] la cebada [...] y las habas y demás leguminosas no tenían precio ni habia quién las comprase..." (IBN ABī ZAR', Raw d al-Qirțās, pp. 572-573).

64 VERnET, "Recherches sur la production et la circulation des céréales", pp. 31-62.

65 DuBy, L'économie rurales et la vie des campagnes.

${ }^{66}$ Le Roy, Histoire du climat depuis l'an Mil. AlexAndre, "Les variations climatiques au Moyen Âge", pp. 183-197; Le climat en Europe au Moyen Age. Dyer, Niveles de vida en la Baja Edad Media. FAGAN, La pequeña Edad del Hielo.

${ }^{67}$ VV.AA, La Croissance agricole du Haut Moyen Âge. Benito I MoncLús, "Et si sterilitas, ut solet, in terra illa fuerit", pp. 82-85. Y, sobre todo, FAGAN, idem, pp. 77-86.

${ }^{68}$ Le Roy, Histoire du climat depuis l'an Mil.

${ }^{69}$ Fagan (La pequeña Edad del Hielo, pp. 77-100) retrasa el arranque del LIA al ciclo 1315-1322, que fue devastador debido a un exceso de lluvias y de frío que prolongó sus efectos sobre la agricultura -en la forma de una reducción a la mitad de la producción de grano-; en la ganadería -entre 1316 y 1320 se produjo lo que él denomina "mortandad de las bestias"- y en los habitantes de Europa hasta 1322 que padecieron hambrunas como consecuencia de los anteriores efectos, y las bajas temperaturas. 


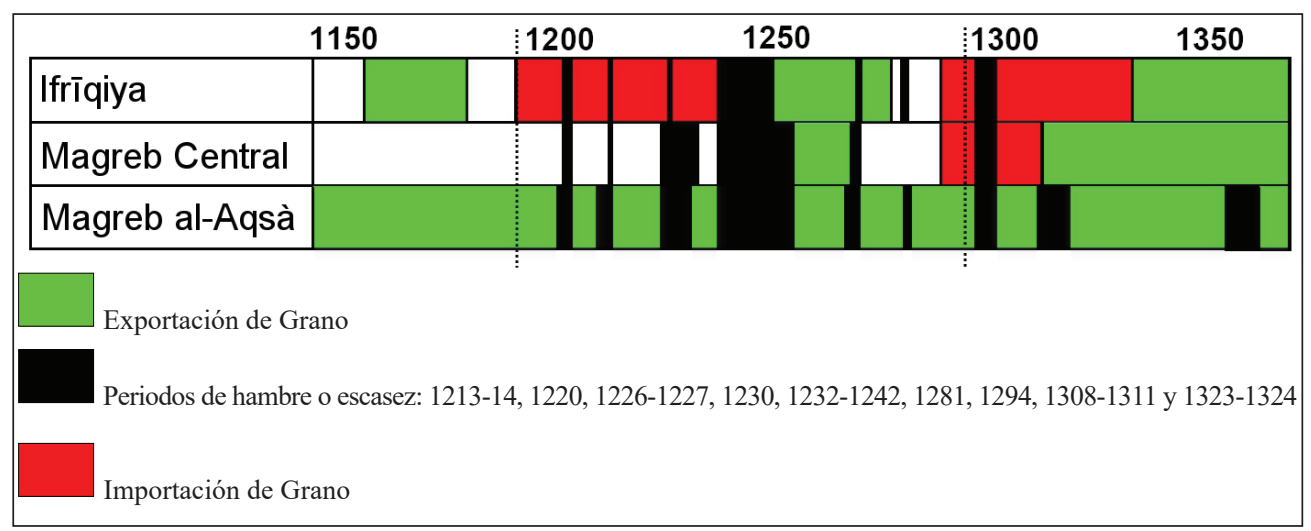

Tabla 3. De la producción, importación y exportación de grano.

Fuente: Vernet: "La production cerealiere dans le maghreb du XIIIè Siecle”, p. 266.

Aquellos estudios sobre los episodios climáticos del siglo XIII pueden ser interrelacionados con el clima en los reinos peninsulares. De hecho, se ha incidido en la importancia de estimar las crisis meteorológicas y de subsistencia desde un punto de vista geográfico regional o global, ya que lo que sucedía en Europa de una forma o de otra tenía su correspondencia en la Península ${ }^{70}$. Desde este punto de vista, el análisis de los datos de Europa occidental permite advertir interesantes coincidencias con las incidencias descritas en el anterior epígrafe (tabla 4), sobre todo al estudiar territorios de fachadas climáticas coincidentes según la clasificación de Köppen-Geiger. Así, para contrastar la fachada mediterránea y centro de la península ibérica (Bsk; Csa) -que incluye, por analogía, las fachadas mediterránea y atlántica del Magreb (Csa)- se han tomado los testimonios de la península itálica y el Languedoc; y, para la fachada atlántica-continental ( $\mathrm{Cfb}, \mathrm{Csb})$ se han considerado los datos de Inglaterra $\mathrm{y}$, superficialmente, de Francia central y el Sacro Imperio.

Como he señalado, para la fachada mediterránea hay que considerar la península italiana y el Languedoc. De la primera se conocen carestías generalizadas en los años $1227-28$ y $1243^{71}$. Cabe señalar que esas tempranas fechas y sus intervalos son bastante coincidentes con lo que se sabe de la Corona de Aragón, lo que llevó a P. Benito a reflexionar sobre el común «model mediterrani de les caresties, diferenciat del model nordic $>{ }^{72}$ alternado, además, con un similar control del comercio de grano por las autoridades municipales y regionales que en Italia ya se producía desde $1250^{73}$. A partir de 1256 las carestías empezaron a focalizarse en el área climática más similar a Castilla y León, esto es, el occidente de la bota ${ }^{74}$ : Liguria y Toscana (1256); Nápoles (1257-59); y, Liguria, Nápoles y Sicilia (1269-72). Por su parte, el análisis de P. Alexandre para el

70 BARRIENDOS, “La climatología histórica en España”, pp. 15-56. Benito I Monclús, "Fams i carestíes a la Mediterrànea occidental”, pp. 179-194.

71 AlbINI, "Un problema dimenticato: carestie ed epidemie nei secoli XI-XIII", pp. 243-270-

72 Benito I Monclús, "Fams i carestíes a la Mediterrànea occidental”, p. 188.

73 Palermo, "Carestie e cronisti nel Trecento", pp. 343-375.

74 Benito I Monclús, "Fams i carestíes a la Mediterrànea occidental”, p. 191, anexo 1. 

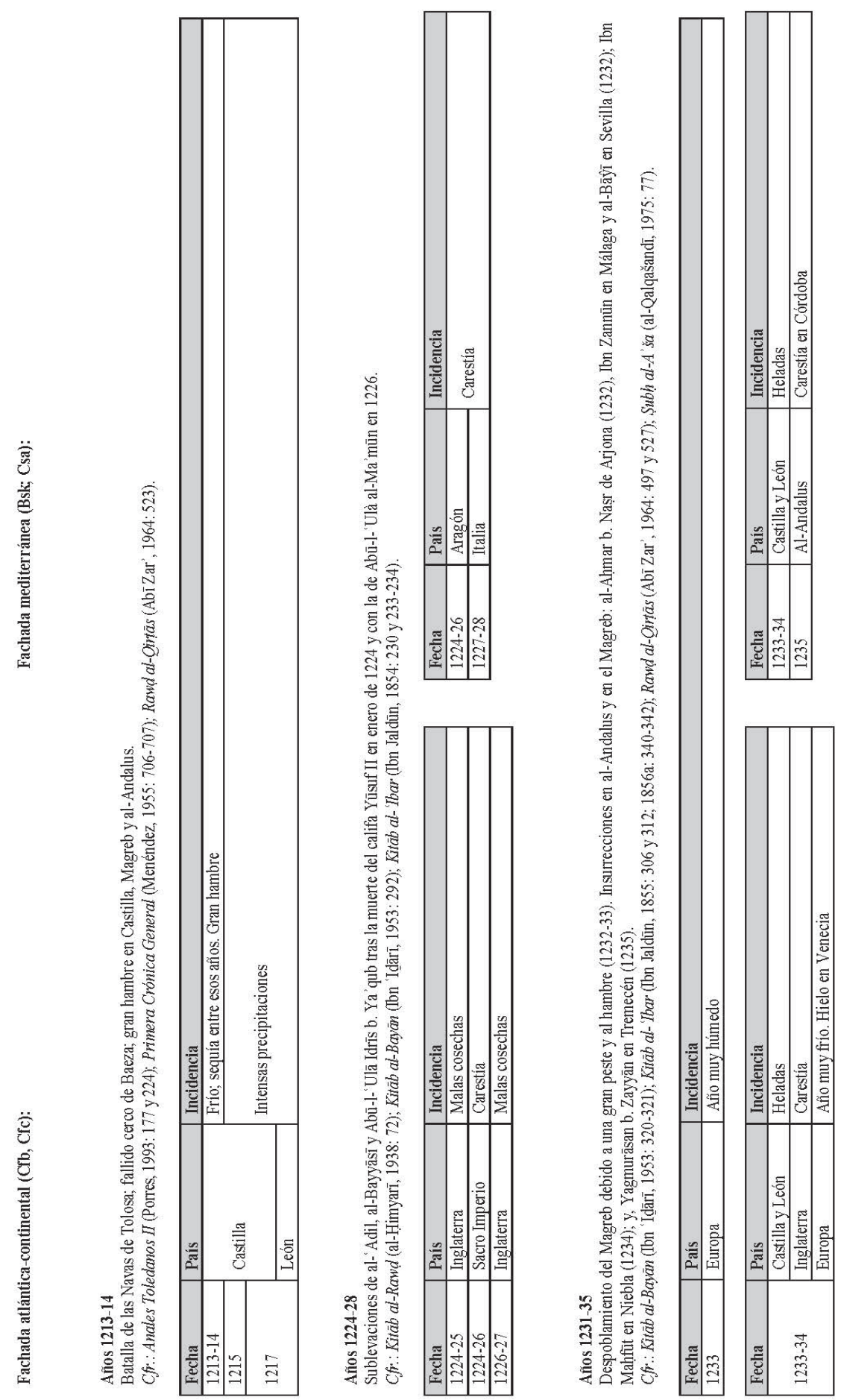


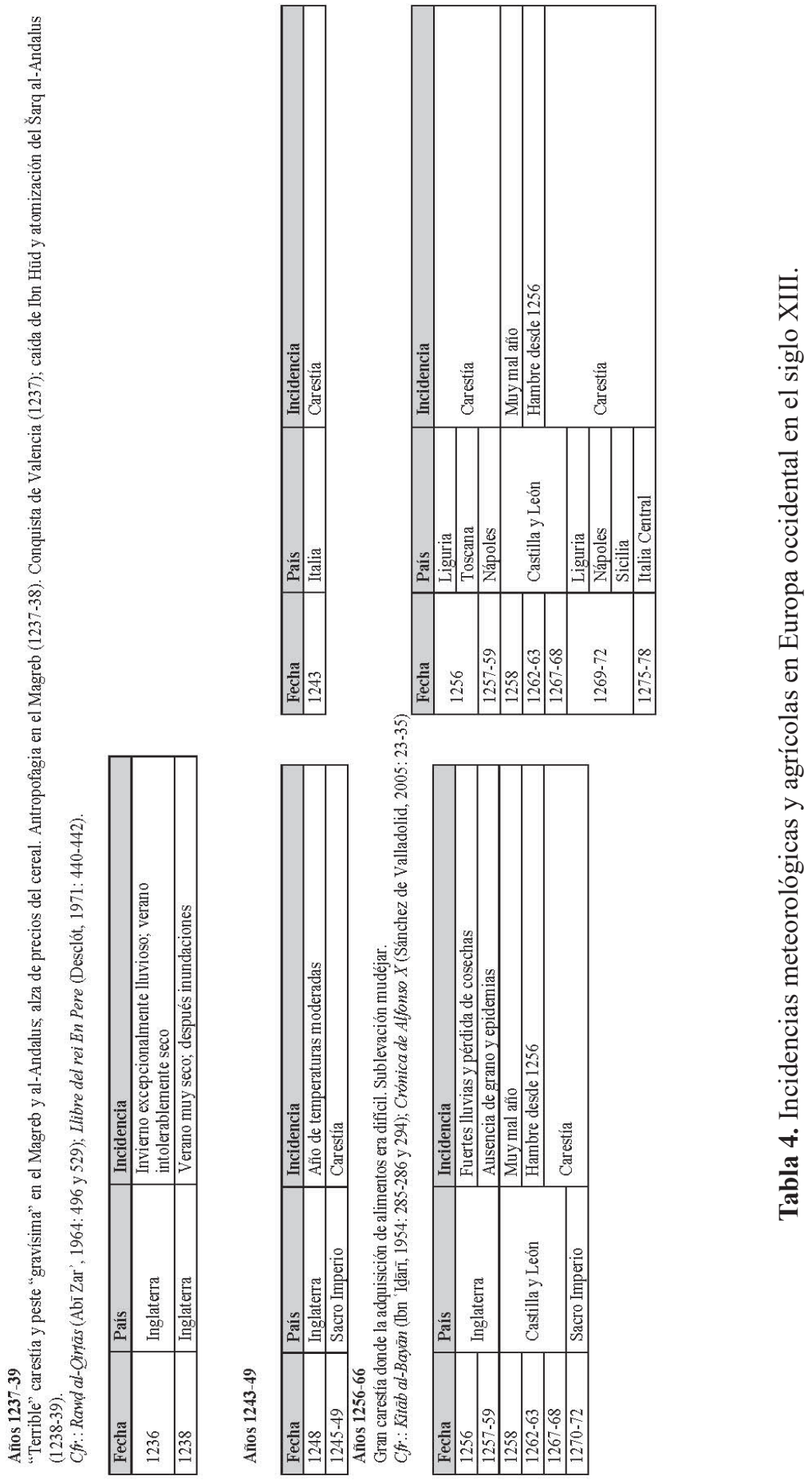


Languedoc indicaba una sucesión de acontecimientos meteorológicos y subsiguientes incidencias en la agricultura que, como había ocurrido en Castilla y León, salpicaron entre 1209 y 1261 aquella tierra y sus lugares más representativos: Tolouse, Narbone, Carcassone y Montpellier, con especial atención al periodo comprendido entre 1256 y 1261 en que las lluvias produjeron inundaciones, y llegó a haber nieve en la última de las localidades citadas ${ }^{75}$.

Para confrontar completamente los datos climáticos y de producción agraria de Castilla y León - esta vez en su fachada atlántica- se observa el caso de Inglaterra, apreciándose también destacables coincidencias. Los rendimientos del obispado de Winchester muestran dos bienios de malas cosechas en $1224-25$ y $1226-27^{76}$. Y un estudio sobre la crónica de Matthew Paris pone de relieve las malas cosechas y los elevados precios que resultaron de las mismas entre 1234 y 1259, haciendo hincapié en que se debieron a causas meteorológicas, y destacando que, entre aquellos años, hubo uno, 1254 , que fue de buenas cosechas y precios bajos ${ }^{77}$. Pero, sobre todo, llama la atención el catastrófico trienio de 1257-59 producido, según la Crónica de Bury St. Edmunds, por una sucesión de fuertes lluvias en 1256; además, se caracterizó por unas fortísimas epidemias y la escasez de grano incluso para su cultivo ${ }^{78}$.

Finalmente, otra vez el estudio de P. Alexandre permite advertir coincidencias con los episodios climáticos del Magreb y de la Europa continental, sobre todo con los más tempranos del siglo XIII. Gracias a su elaborada tabla se identifican los principales acontecimientos climáticos en los ciclos 1212-14; 1223-26; 1227-29; 1231-35; 123739 y 1264-66. De ellos, en Francia central y el Sacro Imperio los años 1223-26 fueron muy húmedos y muy fríos incluso en verano, lo que terminó provocando carestías; el bienio 1233-34 fue muy húmedo en su primer año, siendo el segundo de un invierno bajas temperaturas y seco, con mucho hielo en toda Europa occidental, hasta el extremo que el Mediterráneo se heló en Venecia ${ }^{79}$. En contraste, el cuatrienio 1245-49 se caracterizó por una prolongada sequedad que afectó a las cosechas ${ }^{80}$.

\subsection{EL CONTEXTO CLIMÁTICO: EL FIN DEL PERIODO CÁLIDO MEDIEVAL}

En su momento, H. Lamb trató de sistematizar el fenómeno de un enfriamiento lento y progresivo, apuntando a un clima oscilante fundamentalmente cálido en el intervalo 1000-1200, que fue seguido por una época de temperaturas bajas entre 1500 y $1700^{81}$. Ello lo demostró al contrastar los cambios de temperatura y el régimen de precipitaciones en Inglaterra con medidas de entre 50 y 150 años, encontrándose que las tem-

75 AleXANDre, Le climat en Europe au Moyen Age, pp. 221-225.

76 Titow, "Evidence of Weather in the Account Rolls", pp. 365-391. Dyer, Niveles de vida en la Baja Edad Media, p. 330, cuadro 19.

77 LE GoFf, "Bulletins météorologiques au XIIIe siècle", pp. 55-70.

${ }^{78}$ SCHOFIELD, "Respuestas a la carestía y al hambre en el mundo rural", pp. 231-233.

${ }^{79}$ Alexandre, Le climat en Europe au Moyen Age, pp. 385-387. Pfister et al., "Winter air temperature", p. 545.

${ }^{80}$ Alexandre, Le climat en Europe au Moyen Age, p. 381 y ss. Menant, "Crisis de subsistencia y crisis agrarias en la Edad Media", p. 16.

${ }^{81}$ Lamb, "The early Medieval warm epoch and its sequel", pp. 13-37; Climate, History, passim. 
peraturas pudieron oscilar hasta $\sim 1,3{ }^{\circ} \mathrm{C}$ mientras las precipitaciones se incrementaron un $10 \%$. Posteriormente, una síntesis de las fuentes medievales en Europa defendió la posibilidad de que en la segunda mitad del siglo XIII arrancara el ciclo de enfriamiento tras aquel Periodo Cálido Medieval, cuya horquilla él afinaba desde el 800 hasta $1250^{82}$. Tal y como manifestaba H. Lamb, ese enfriamiento sería el precedente de la Pequeña Edad Glaciar ajustada entre 1550 y 1850.

Las simulaciones realizadas en los últimos años ${ }^{83}$ sostienen aquella hipótesis, ciñéndola al periodo $\sim 950 \sim 1250^{84}$. Sus características principales se concretarían en líneas generales en unos suaves inviernos, unos veranos secos y una proliferación de singularidades hídricas tanto positivas como negativas; si bien ponderados según la geografía. $\mathrm{Su}$ naturaleza se ha tratado de definir con diversas variables ${ }^{85}$, siendo una de las más sugerentes aquella que se refiere a la influencia de la actividad solar ${ }^{86}$. En el otro extremo, otros investigadores han tratado de explicar al cambio de tendencia desde inicios del siglo XIII -recuérdense las crisis de 1213-17, 1224-28 y 1232-35 en Europa y el Magreb antes aludidas-, siendo una de las hipótesis más plausibles la de una prolongada sucesión de eventos volcánicos, pues el periodo 1100-1260 quedó registrado en el hielo antártico y groenlandés como de gran actividad eruptiva ${ }^{87}$; a esa evidencia de expulsión de sólidos a la atmósfera se uniría la del efecto de los gases de efecto invernadero provocados por la deforestación y el cultivo de la tierra ${ }^{88}$.

De la misma forma que aún quedan dudas sobre su origen, tampoco queda clara su afección. Existe cierto consenso en que fue diacrónica en el espacio y el tiempo ${ }^{89}$, lo que para $\mathrm{J}$. Guiot ${ }^{90}$ se pudo traducir en un enfriamiento desde el suroeste de Europa a partir de 1250 , hasta su definitiva extensión por el resto del continente en torno a

82 Alexandre, "Les variations climatiques au Moyen Âge", pp. 194-195.

83 Osborn et al., "Simulated climate change during the last 1,000 years". ManN et al., "Proxy-based reconstructions of hemispheric and global surface temperature", pp. 13252-13257. MANN et al., "Global Signatures and Dynamical Origins of the Little Ice Age", pp. 1256-1260. GraHAM et al. "Support for global climate reorganization", pp. 1217-1245.

${ }^{84}$ Hughes y DíAz, "Was there a 'Medieval Warm Period', pp. 109-142. Bradley et al., "The climate of the last millennium", pp. 105-141. Goosse et al., "The origin of the European "Medieval Warm Period", pp. 99113; Goosse et al., "The role of forcing and internal dynamics", pp. 2847-2866. Guiot et al. "Growing season temperatures in Europe". Nótese que son valores aproximados todavía sujetos a discusión. Esto se debe a la variabilidad de datos según la geografía, y, sobre todo, al efecto del cambio climático sobre cada una de las fachadas climáticas.

${ }^{85}$ Free y Roвоcк, "Global warming in the context of the Little Ice Age”, pp. 19057-19070. JONES y MANN, "Climate over past millennia".

86 Bradley et al., "The climate of the last millennium", pp. 105-141. Goosse et al., "The role of forcing and internal dynamics", 2847-2866.

87 Stothers y Rampino, "Historic Volcanism, European Dry Fogs", pp. 411-413. Robock, "Volcanic eruptions and climate", pp. 191-219. ATwell, "Volcanism and Short-Term Climatic Change", pp. 29-98, y las simulaciones de Goosse et al., "The origin of the European "Medieval Warm Period" y OsBORN et al., "Simulated climate change during the last 1,000 years".

${ }^{88}$ MatThews et al., "Natural and anthropogenic climate change", pp. 461-479. Goosse et al., "The origin of the European "Medieval Warm Period", pp. 99-113.

${ }^{89}$ Bradley et al., "Climate in Medieval time", pp. 404-405. Goosse et al., "Internal and forced climate variability during the last millennium", pp. 1345-1360.

90 GUIOT et al., "Growing season temperatures in Europe". 
$1400^{91}$. Por su parte, algunos defensores del episodio volcánico extremo apuntan a un proceso más drástico: R. B. Stothers trató de establecer 1258 como el punto de inflexión a partir de una violenta erupción, ya que ese año en Inglaterra las temperaturas bajaron, y se produjo un colapso de los cultivos con el consiguiente hambre; de hecho, en ese año, y el de 1259, una plaga se extendió, y el invierno de 1260-61 fue muy frío $0^{92}$. Estas fechas coincidirían con muchas fuentes de las que se ha recogido referencias a años malos con proliferación de carestías a partir de 1256; año, por cierto, en que se registró una erupción, que duró 52 días, cerca de la ciudad árabe de Medina ${ }^{93}$. En todo caso, la prolongación en el tiempo de esos años sería conforme al impacto del enfriamiento de la temperatura de superficie después de una gran erupción, que se sitúa entre 1 y 5 años, siendo el intervalo de 2 a 3 años el más habitual según los registros actuales ${ }^{94}$.

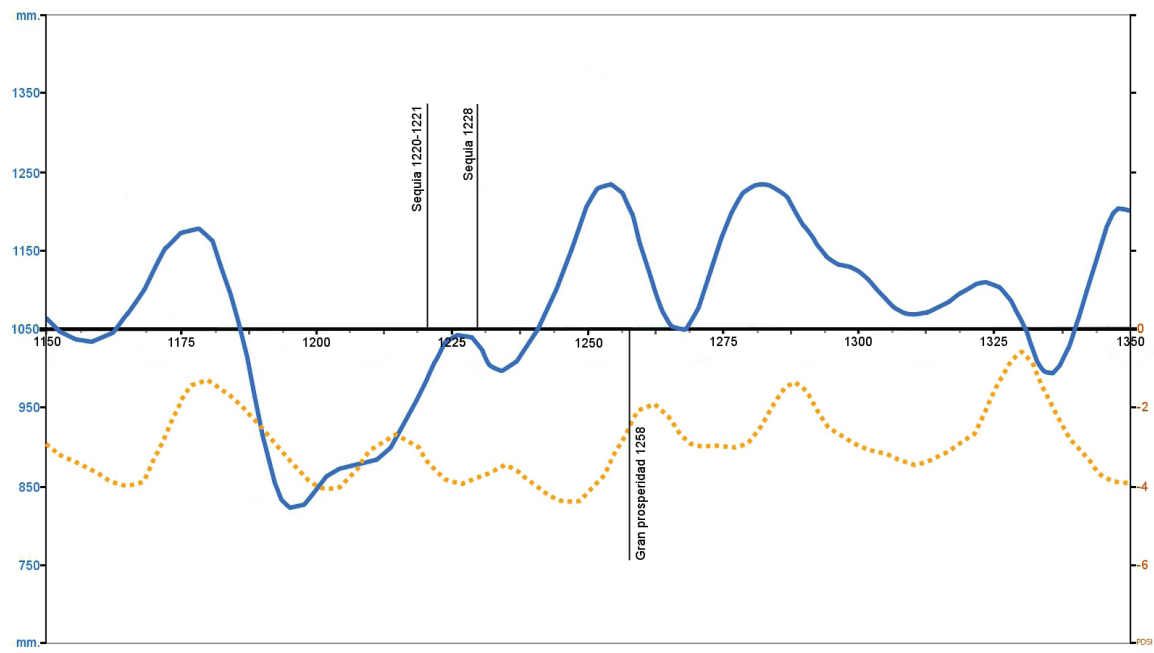

Fig. 3. Línea continua: Media de precipitaciones en el área húmeda de Marruecos (de TILL y GUIOT, "Reconstruction of precipitation in Morocco since 1100 A. D", fig. 3 (1), p. 344). Línea discontinua: Reconstrucción del PDSI medio en sus medias de febrero-junio usando un filtro de 20 años a partir de los datos del periodo 1931-2001 (de ESPER et al., "Longterm drought severity variations in Morocco", fig. 2). Las anotaciones corresponden a la información proporcionada por el Rawḍ al-Qirțās.

${ }^{91}$ Lo que tendría cierta concordancia con algunos proxies estudiados en los últimos años que sitúan el fin del MWP en esa última fecha; como por ejemplo en las costas gallegas. Desprat et al., "Revealing climatic variability of the last three millennia", pp. 63-78.

92 "In the year 1259, a rain of sulphuric acid aerosols and tiny glass shards originating from one of the greatest volcanic eruptions of the past two millennia fell out of the stratosphere onto the North and South polar ice caps (...) On the plausible assumption that this event had to have been a tropical eruption, the total production of sulphuric acid has been estimated as $\sim 300$ megatons (...) and possibly as much as $\sim 600$ megatons". STотHERs, "Climatic and demographic consequences of the massive volcanic eruption of 1258", p. 361.

${ }^{93}$ CAmp et al., "The Madinah eruption, Saudi Arabia", pp. 489-508. Mouftr et al., "The 1256 AD alMadinah historic eruption geosite", pp. 1069-1070.

${ }^{94}$ Stothers, "Climatic and demographic consequences of the massive volcanic eruption of 1258 ", pp. 364-65. 
De una forma o de otra, si H. Lamb propuso entre el pico del óptimo medieval de 1100 y el Mínimo de Maunder (en torno al año 1700) un descenso medio de entre 1,2 y $1,4{ }^{\circ} \mathrm{C}$, circunscrito al periodo medieval, varias simulaciones tienden a mostrar un descenso progresivo a lo largo del siglo XIII ${ }^{95}$. Algunas ${ }^{96}$ plantean para el conjunto de Europa Occidental descensos medios desde el inicio de 1200 hasta 1300 de $\sim 0,15^{\circ} \mathrm{C}$ en verano a $\sim 0,12{ }^{\circ} \mathrm{C}$ en invierno; cifras medias que podrían esconder datos extremos de gran impacto. En todo caso, fuera cual fuera la naturaleza del cambio de tendencia en el clima acaecido en el siglo XIII, lo cierto es que parece que hubo un enfriamiento e intermitente humidificación del continente europeo, sobre todo en sus inviernos ${ }^{97}$, que tuvo su análoga afección en el Magreb en la forma de crisis puntuales como los episodios 1213-14, 1224-28 y 1233-34, haciendo, también, más evidentes y duras las sequías. Si en la península ibérica el análisis estadístico de las fuentes ${ }^{98}$ ha confirmado un aumento en la incidencia hídrica de los ríos de la fachada atlántica conforme avanzó el siglo, los proxies sedimentarios analizados ${ }^{99}$ indican la misma tendencia en toda ella; fenómeno que, como ya he señalado más arriba, se aprecia en la síntesis dendroclimática de E. Marique y A. Fernández-Cancio ${ }^{100}$. Acelerado el proceso a mitad de siglo, se puede advertir su desigual incidencia en el Magreb justo a partir del año 1258, que fue de muy buenas cosechas, tal y como relata Ibn Abī Zar' en su Raw d al-Qirțās. Más aún, dado que la ausencia de malas cosechas se prolongó hasta 1264, puede inferirse que el enfriamiento y proliferación de precipitaciones -como se ha descrito en los estudios dendrocronológicos y del PDSI (Palmer Drought Severity Index) en el Marruecos húmedo (fig. 3) ${ }^{101}$ - fue beneficioso para ese territorio, y se produjo de forma intermitente y prolongada durante aproximadamente los siguientes cien años ${ }^{102}$.

\section{CONCLUSIONES}

En la introducción indicaba la existencia de dos trabajos ${ }^{103}$ los cuales habían contemplado puntualmente la incidencia del clima en el desarrollo de algunos acontecimien-

95 Mann y Jones, "Global surface temperatures over the past two millenia". Osborn et al., "Simulated climate change during the last 1,000 years". MANN et al., "Proxy-based reconstructions of hemispheric and global surface temperature”, pp. 13252-13257; "Global Signatures and Dynamical Origins”, pp. 1256-60.

96 Goosse et al., "The origin of the European "Medieval Warm Period" y "The role of forcing and internal dynamics", pp. 2847-2866.

97 FAGan, La pequeña Edad del Hielo, pp. 57-58.

98 Benito et al., "Magnitude and frequency of flooding in the Tagus Basin", pp. 171-192.

99 VAlero-Garcés et al., "Human impact since Medieval times", pp. 24-49. MARTín-Puertas et al., “Arid and humid phases in southern Spain”, pp. 907-921. LóPEZ-DíAs et al., "Biomarkers in a peat deposit in Northern Spain", pp. 3538-3546. BARreIro Lostres et. al., "Facies sedimentarias de la laguna kárstica de La Parra", pp. 109-112. Barreiro Lostres et al., "Evolución sedimentaria del lago kárstico de La Parra". pp. 179-193

${ }^{100}$ Marique y Fernández-CANCio, "Extreme climatic events in dendroclimatic”, pp. 123-138.

101 ESPER et al., "Long-term drought severity variations in Morocco".

102 Till y Guiot, "Reconstruction of precipitation in Morocco since 1100 A. D", pp. 337-351.

103 Arié, España Musulmana. Reglero, "Les disettes dans le royaume de Castille”, pp. 309-342. 
tos peninsulares de los siglos XIII y XIV. En otro trabajo citado ${ }^{104}$ se daba un paso más, llamando la atención sobre el papel que podría haber tenido un clima oscilante a la baja en las revueltas urbanas en al-Andalus del siglo XIII. La argumentación señalaba que si, debido a la presión militar castellano-aragonesa, una gran masa migratoria se encerraba en las ciudades bajo el amparo de los autoproclamados califas, emires, arráeces o las aljamas, estaba claro que entrarían en juego otros factores decisivos como la producción agrícola para asegurar la subsistencia de sus antiguos y nuevos habitantes. Dado que el periodo fue socialmente inestable y proclive a la continua insurgencia, es evidente que no sólo el miedo a la conquista feudal azuzó la efervescencia social, sino, como indican las fuentes árabes, las revueltas podrían tener su raíz - por ejemplo- en una recurrente carestía de alimentos. En ese sentido, la Primera Crónica General ${ }^{105}$ hace repetidas menciones a acciones militares tales como saqueos y destrucción de cosechas, que debieron tener un importante papel en aquellas carestías ${ }^{106}$. Sin embargo, en aquel escenario el resultado de un estado de guerra por si solo no puede explicar la proliferación de hambrunas y sus consecuencias en los pobladores, precisamente por el limitado alcance las acciones militares en la geografía. Y, en ese sentido, las fuentes árabes, además de citar aquellas carestías y subsiguientes hambrunas, salpican sus páginas de acontecimientos meteorológicos adversos con una frecuencia no vista en sus anteriores páginas. Ese factor me ha hecho relacionar aquellas referencias con un clima que, aparentemente, estaba teniendo un papel cada vez más protagonista, tanto como el propio factor humano ${ }^{107}$.

Consciente, como indicaba en la introducción, de la limitación de las fuentes cronísticas, sin embargo la citada proliferación de eventos, que anunciaba una oscilación climática a la baja arrancado el siglo XIII, invita a cuestionar su relación con la rápida sucesión de acontecimientos políticos en el Magreb al-Aqsà y al-Andalus, hasta el extremo de contribuir a la aniquilación del Imperio almohade y con él casi todo alAndalus. Soy consciente que desde un punto de vista metodológico puede resultar inaceptable establecer una causalidad con unas fuentes tan limitadas, pero el actual conocimiento del clima histórico, la coincidencia de fechas, la evidente claridad con que algunas explican el impacto de un adverso clima, y la ausencia de una explicación más allá de las corrientes de opinión, la ideología o el ambiente cultural en el Islam occidental permiten sostener la hipótesis aquí planteada, que futuros estudios arqueológicos y paleoclimáticos podrían corroborar. En todo caso, al contrastar los datos recopilados y sintetizados en las tablas 1, 2 y $\mathbf{4}$ se advierten evidentes coincidencias que adquieren una mayor significación al discernirse según su geografía. Estas coincidencias se estructurarían de la siguiente forma:

1.- Episodio de oscilaciones climáticas 1213-1221; de fuerte impacto en el Mediterráneo occidental y algunos puntos de la Europa continental. Debilitó a un Imperio almohade previamente derrotado en Las Navas de Tolosa. Las consecuencias

${ }^{104}$ Frey SÁNChEZ, "Ciudades y poder político en al-Andalus", pp. 845-885.

${ }^{105}$ Primera Crónica General, pp. 678-679.

106 Segura Graiño, "La tala como arma de guerra en la Frontera", pp. 717-724 y "Les recherches sur le climat dans la Couronne de Castille", pp. 147-162.

${ }^{107}$ Dyer, Niveles de vida en la Baja Edad Media, pp. 326-344. 
de tal debilitamiento eclosionaron en el trienio 1224-26 con las sublevaciones dinásticas de al-'Adil, al-Bayyāsī y Abū-l- 'Ulā Idrīs b. Ya' qub, y Abū-l-'Ulà al-Ma'mūn, que terminaron provocando la deslegitimización de la autoridad califal a ojos los musulmanes occidentales. En el campo cristiano la crisis climática se contextualiza en un alto en su expansión; en Castilla agravado, si acaso, por la muerte de Alfonso VIII y la crisis de la regencia.

2.- Episodio de oscilaciones climáticas 1224-28; de impacto global. Escenificó la pérdida de la autoridad califal en medio de un paisaje de carestías y subsiguiente descontento en que arrancaron las primeras sublevaciones urbanas andalusíes a rebufo de la hūdí (1228). Su éxito vino dado por corrientes de opinión de gran participación ciudadana -como indicó Ibn 'Id̄ārî108 - que terminaron otorgándole la legitimidad necesaria, la ba ya. En ese contexto se produjo, en un Magreb más tardíamente sacudido por la crisis climática, la irrupción de los benimerines en el Magreb al-Aqsà (1228), y la sublevación de Abū Zakariyā' Yahyā b. Hafṣ (1229).

3.- Episodio de oscilaciones climáticas 1232-1235; de desigual impacto. Asistió a la recuperación de Castilla y León: se produjo un nuevo impulso en su expansión territorial con las conquistas de Cáceres (1229), Mérida y Badajoz (1230), que significaron las primeras derrotas de Ibn Hūd. La imposibilidad de éste para frenar a aquéllos quebró su apoyo popular, y provocó las sublevaciones de al-Aḥmar b. Nașr en Arjona (1232) y de Ibn Maḥūt en Niebla (1234). El éxito y consolidación de ambos debe enmarcarse en el bienio 1233-34, que fue muy seco y frío, lo que explicaría el nuevo alto feudal. Aquella división andalusí y el impacto de la carestía trajeron consigo la caída de la simbólica ciudad de Córdoba al año siguiente. En el Magreb, área geográfica de efecto más prolongado sobre la agricultura (tabla 3), el Imperio almohade siguió deteriorándose con la sublevación de Yagmurāsan en Tremecén (1235).

4.- Episodio de oscilaciones climáticas 1237-39; de notables consecuencias en alAndalus y el Magreb, contextualiza el colapso del emirato hudī en 1238. Esos años asistieron al derrumbe de al-Andalus con la conquista de Valencia (1237) y las posteriores de Murcia, Jaén y Sevilla (1243-1248). La crisis social se acrecentó, como lo demuestra la secesión de poderes locales en todo al-Andalus y su adhesión al emergente emirato nazarí como indicó Ibn 'Id̄ārī al referirse a Granada: "convinieron sus habitantes en destituir a Ibn Hūd y proclamar a Ibn Nāṣr" ${ }^{109}$. En Murcia en dos años llegaron a sucederse tres personajes en su gobierno: al-Wātiq b. Hūd, 'Azīz b. Jațāāb y Zayyān b. Mardanīš; todos, en mayor o menor medida, respaldados por la población ${ }^{110}$.

5.- Comienzo de la fase depresiva en la mitad del siglo XIII (desde 1256); de impacto global. Esta fase de largo alcance incidió principalmente en Castilla y León con un episodio climático muy duro (1256-1263) de carestía y subsiguiente hambre, el cual, luego, en 1264-65, se extendió a los territorios mudéjares. Este episodio contextualiza el endurecimiento de las políticas coloniales alfonsinas y, por extensión, la revuelta mudéjar de aquellos años. La consolidación de la oscilación depresiva se plasma en un estudio dendroclimático ${ }^{111}$; una ralentización de la presión humana en Girona a partir de $1280^{112}$ y en registros ambientales localizados en Asturias, que señalan el decenio 1270-80 ${ }^{113}$.

\footnotetext{
108 IBN 'ID̄ĀR̄̄, Kitāb al-Bayān al-Mugrib, I, p. 320.

109 IBN 'ID̄̄̄ī, Kitāb al-Bayān al-Mugrib, I, pp. 109-111

110 Frey SÁnChez, "Cuando se difundió la fama de Ibn Hūd por al-Andalus...”, pp. 419-432.

111 Marique y Fernández-CANCIO, "Extreme climatic events in dendroclimatic”, pp. 123-138.

112 López SÁEz et al., "Historia de la vegetación en el litoral norte de Girona”, pp. 13-28.

113 López-Días et al., "Biomarkers in a peat deposit in Northern Spain”, pp. 3538-3546.
} 
El último punto supone la ratificación de una tendencia puesta de relieve en el resto de Europa, y pivotada en torno al deterioro general del clima tanto en la fachada atlántica-continental como en la mediterránea entre 1256 y 1259. Estos años se caracterizaron por una proliferación de lluvias y, a la vez, episodios de calidez prolongada que arruinaron cosechas, provocaron carestías generalizadas y brotes de pestilencia. Los estudios que apuntan a un deterioro climático producto de una significativa actividad volcánica tienen en aquellos años una validación documental de sus prolongados efectos. Por ello, si empezado el siglo XIII se advierte una tendencia crítica que arrancó con la crisis de 1213-14, sugiero considerar una sucesión de eventos cataclísmicos documentados entre 1256 y 1258 que catalizara la tendencia hacia el posterior enfriamiento de la Pequeña Edad de Hielo. Resulta, en todo caso, especialmente significativo que en 1258-59 fuera en el Magreb de una excepcional prosperidad caracterizada por buenas y abundantes cosechas. Esto, desde el punto de vista climático vuelve a advertir de la importancia de considerar las fachadas climáticas y el desigual impacto de los cambios. El testimonio de Ibn Abī Zar' introduce a un periodo de mayor estabilidad productiva magrebí que caracterizaría la segunda mitad del siglo XIII y la primera del XIV como ilustra la tabla 3. Desde un punto de vista político también resulta especialmente significativo que la tormenta política amainase, y que, únicamente, el acontecimiento más reseñable, que es la disolución del califato almohade y, por ello, la final consolidación del sultanato benimerín en Magreb al-Aqsà, se sitúe cerca de la crisis de subsistencia situada por Ibn 'Id̄ārī entre 1264 y 1265 . Finalmente, en la península ibérica se advierten interesantes consecuencias respecto a esa crisis de subsistencia y a la que venía arrastrando Castilla desde 1256: además del citado endurecimiento de la política colonial de Alfonso X desde 1257, se podría contextualizar la revuelta mudéjar de 1264-66; y, ante la debilidad castellana y lo abrumador de su lucha en Andalucía, la intervención en el territorio murciano de una corona aragonesa menos impactada por las últimas crisis agrícolas.

\section{AGRADECIMIENTOS}

Agradezco la amable y generosa aportación bibliográfica de los profesores C. Reglero, J. M. Vaquero y J. S. Carrión, quienes atendieron mis peticiones para consultar bibliografía para mí inaccesible. También a los evaluadores, quienes con sus amables sugerencias, me han permitido mejorar sustancialmente algunos contenidos del artículo.

\section{BIBLIOGRAFÍA}

\subsection{FUENTES}

Anales Toledanos, I y II, en Porres Martín-Cleto, J. (ed.), Toledo, Instituto Provincial de Investigaciones y Estudios Toledanos, 1993.

Crónica de Bernat Desclót o llibre del rei En Pere, en Soldevilla, F. (ed.): Les quatre grans cròniques. Barcelona, Institut d'Estudis Catalans, 1971. 
Himyarī [= al-Himyarī], Kitāb al-Rawọ al-Mi tāar, Lévi-Provençal, E. (ed.), Leyden, E. J. Brill, 1938.

Ibn Abī Zar', Rawọ al-Qirțās, Huici Miranda, A. (ed.), Valencia, Anubar, 1964.

Ibn 'Idāāī, Kitāb al-Bayān al-Mugrib, I en Huici Miranda, A. (ed.): Colección de Crónicas Árabes de la Reconquista. Tetuán, Instituto de Estudios e Investigación Hispano-Árabe, 1953.

Ibn 'Idārī, Kitāb al-Bayān al-Mugrib, II en Huici Miranda, A. (ed.): Colección de Crónicas Árabes de la Reconquista. Tetuán, Instituto de Estudios e Investigación Hispano-Árabe, 1954.

Ibn Jaldūn, Kitāb al- 'Ibar en McGuckin de Slane, W. (ed.): Histoire des Berbéres et des dynasties musulmanes de l'Afrique Septentrionale, Argel, 1852, 1854 y 1856 (=1856a) y 1856 (=1856b).

Primera Crónica General, en Menéndez Pidal, R. (ed.). Madrid, Gredos, 1955.

Qalqašandī [= al-Qalqašandī], Șubḥ al-A’̌̌a, L. Seco de Lucena (ed.). Valencia, Anubar, 1975.

\subsection{LITERATURA}

AguAdé NiETo, S., "En los orígenes de una coyuntura depresiva la crisis agraria de 1255 a 1262 en la Corona de Castilla". Anuario de Estudios Medievales, 19 (1989), pp. 243-270.

AlbINI, G., "Un problema dimenticato: carestie ed epidemie nei secoli XI-XIII. Il caso emiliano" en Comba, R. y Naso, I. (dir.), Demografia e società nell'Italia medievale (secc. IX-XIV), Cuneo, 1994, pp. 47-67.

Alexandre, P., "Les variations climatiques au Moyen Âge (Belgique, Rhénanie, Nord de la France)". Annales E.S.C., 32 (1977), pp. 183-197.

AleXANDre, P., Le climat en Europe au Moyen Age, contribution à l'histoire des variations climatiques de 1000 à 1425, d'après les sources narratives de l'Europe occidentale. Paris, Editions de l'Ecole des hautes études en sciences sociales, 1987.

AriÉ, R., España Musulmana (siglos VIII-XV), en Tuñón de Lara, J. M. (dir.), Historia de España, III. Barcelona, Ariel, 1984.

Atwell, W. S., "Volcanism and Short-Term Climatic Change in East Asian and World History, c. 1200-1699”, Journal of World History, 12/1 (2001), pp. 29-98.

Barreiro Lostres, F.; Moreno Caballud, A. y Valero-Garcés, B. L., "Facies sedimentarias de la laguna kárstica de la Parra (Cuenca) durante los últimos 1600 años cal. BP”. Geogaceta, 51 (2011), pp. 109-112.

Barreiro Lostres, F.; Moreno, A.; Giralt, S. y Valero Garcés, B. L., "Evolución sedimentaria del lago kárstico de La Parra (Cuenca) durante los últimos 1600 años: paleohidrología, clima e impacto humano". Cuadernos de investigación geográfica, 39/1 (2013), pp. 179-193.

BARRIENDOS VAllvé, M., "El clima de la península Ibérica a través de los registros históricos" en Ibáñez Estévez, J. J.; Valero Garcés, B. L. y Machado, C. (coords.), El paisaje mediterráneo a través del espacio y del tiempo: implicaciones en la desertificación. Barcelona, GeoformaCSIC, 1997, pp. 343-362.

BARriendos VAllvé, M., "La climatología histórica en España. Pioneros resultados y perspectivas de la investigación" en J. C. García Cordón (coord.): La reconstrucción del clima en la España preindustrial. Santander, Universidad de Cantabria, 2000, pp. 15-56.

BARriendos VAllvé, M., "La reconstrucción del clima a partir de testimonios históricos: Encrucijada metodológica entre la fuente cualitativa y su expresión numérica". Índice, 50 (2012), pp. 18-20. 
Benito, G; Díez-Herrero, A. y Fernández de Villalta, M., "Magnitude and frequency of flooding in the Tagus Basin (Central Spain) over the last millennium". Climatic Change 58 (2003), pp. 171-192.

BENito i Monclús, P., "Et hoc facimus propter necessitatem famis...” Possibilitats de les fonts documentals catalanes per a l'estudi de les crisis alimentàries dels segles X-XIII". Acta historica et archaeologica mediaevalia, 25 (2003), pp. 39-62.

BENITO I Monclús, P., "Fams i carestíes a la Mediterrànea cccidental durant la baixa edad mitjana. El debat sobre "la crisis de la crisi", Recerques, 49 (2004), pp. 179-194.

Benito i Monclús, P., "Et si sterilitas, ut solet, in terra illa fuerit..” Frecuencia, longevidad y gravedad de las carestías en Cataluña durante la "fase de crecimiento" de la economía medieval (siglos XI-XIII)" en Oliva Herrero, H. R. y Benito i Monclús, P. (eds.), Crisis de subsistencia y crisis agrarias en la Edad Media, Sevilla, Universidad de Sevilla, 2007, pp. 79-110.

Bradley, R. S.; Briffa, K. R.; Cole, J.; Hughes, M. K. and Osborn, T. J., "The climate of the last millennium" en Alverson, K.; Bradley, R. S. y Pettersen, T.F. (eds.), Paleoclimate, Global Change and the Future, Berlin, 2003, pp. 105-141.

Bradley, R. S.; Hughes, M. K. y Diaz, H.F., "Climate in Medieval time”. Science, 302 (2003), pp. 404-405.

BrunschVig, R., La Berberie orientale sous les Haflides des origines a la fin du XV siecle, 2 vol. Paris, A. Maisonneuve, 1940-1947.

CACHo I., VAlero-Garcés B. y González SAMPÉriz P., "Revisión de las reconstrucciones paleoclimáticas en la península Ibérica desde el último periodo glacial", en Pérez Fiz, F. y Boscolo R. (eds.), Clima en España: pasado, presente y futuro, Madrid, MCI, MMAMRM y CLIVAR, 2010, pp. 9-24.

CAmp, V. E.; Hooper, P. R. and White, D. L., "The Madinah eruption, Saudi Arabia: magma mixing and simultaneous extrusion of three basaltic chemical types", Bull. Volcanol. 49 (1987), pp. 489-508.

Creus Novau, J.; Peña Monné, J. L.; Barriendos Vallvé, M.; Moreno, A.; González Sampériz, P.; Sancho Marcén, C.; Valero, B.; Pérez Alberti, A.; Saz, M. A. y Constante A., "Los estudios de Paleoclimatología en España" en Cuadrat Prats, J. M. y Martín Vide, F. J. (dirs.), La climatología española: pasado, presente y futuro. Zaragoza, Prensas de la Universidad de Zaragoza, 2007, pp. 249-282.

Crowley, T. J.; Baum, S. K.; Kim, K. Y. and Hyde, W. T., "Modeling ocean heat content changes during the last millennium", Geophys. Res. Lett., 30 (2003), p. 1932.

De las Cagigas, I., Los mudéjares, II. Madrid, Instituto de Estudios Africanos, 1949.

De las Cagigas I., Sevilla almohade y los últimos años de su vida musulmana, Madrid, CSIC, 1951.

DeSPRAT, S.; SÁNCHEZ-GoÑI, M. F.; Loutre, M. F., "Revealing climatic variability of the last three millennia in northwestern Iberia using pollen influx data". Earth and Planetary Science Letters, 213 (2003), pp. 63-78.

Diaz, H. F.; Trigo, R.; Hughes, M. K.; Mann, M. E.; XoplaKi, E. y Barriopedro, D., "Spatial and temporal characteristics of climate in medieval times revisited", American Meteorological Society, Nov. 2011 (2011), pp. 1487-1500.

Domínguez-Castro, F.; Vaquero, J. M.; Marín, M.; Gallego, M. C. y García-Herrera, R., "How useful could Arabic documentary sources be for reconstructing past climate?". Weather, 67/3 (2012), pp. 76-82. 
Domínguez-Castro, F.; de Miguel, J. C.; Vaquero, J. M.; Gallego, M. C.; García-Herrera, R., "Climatic potential of Islamic Chronicles in Iberia: Extreme droughts (AD 711-1010)". Holocene (en prensa).

Duby, G., L'économie rurales et la vie des campagnes dans l'Occident médiéval: France, Anglaterre, Empire (IXe-Xv siècles). Paris, Aubier, 1962.

DufourcQ, CH. E., L'expansió catalana a la Medieterrània Occidental; segles XIII i XIV, Barcelona, Vicens Vives, 1969.

Dyer, CH., Niveles de vida en la Baja Edad Media. Barcelona, Crítica, 1991.

Esper, J.; Frank, D.; Büntgen, U.; Verstege, A; Luterbacher, J. y Xoplaki, E., "Long-term drought severity variations in Morocco", Geophisical Research Letters, 34/L11702 (2007), doi:10.1029/2007GL030844

FAGAn, B., La pequeña Edad del Hielo, Barcelona, Gedisa, 2008.

Fagan, B., El gran calentamiento. Cómo influyó el cambio climático en el apogeo y caída de las civilizaciones, Barcelona, Gedisa, 2009.

FIERro, M. I., "Doctrinas y movimientos de tipo mesiánico en al-Andalus" en De la Iglesia Duarte, J. I. (Coord.), Milenarismos y Milenaristas en la Europa Medieval. IX Semana de Estudios Medievales, Logroño, Instituto de Estudios Riojanos, 1999, pp. 159-176.

Free, M. y Robock, A., "Global warming in the context of the Little Ice Age", Journal of Geophysical Research, 104/16 (1999), pp. 19057-19070.

Frey SÁnchez, A. V., "Cuando se difundió la fama de Ibn Hūd por al-Andalus.... el papel de las ciudades en la sublevación hūdí de 1228". Actas del III Congreso de Historia de Andalucía. Córdoba, 2001, pp. 419-432.

FREY SÁNCHEZ, A. V., "La estructura de la propiedad de la tierra en Murcia durante la conquista castellana". Estudios de Historia de España, IX (2007), pp. 49-76.

Frey SÁnCHEZ, A. V., "Ciudades y poder político en al-Andalus. Una hipótesis sobre el origen de las revueltas urbanas en Murcia en el siglo XIII”. Anuario de Estudios Medievales, 44/2 (2014), pp. 845-885.

Frey SÁnchez, A. V., "El origen y expansión almorávide en el contexto del Periodo Cálido Medieval". Edad Media. Revista de Historia, 17 (2016), pp. 225-253.

Furió, A., "Disettes et famines en temps de croissance: une révision de la crise de 1300: le royaume de Valence dans la première moitié du XIV siècle" en Bourin, M.; Menant, F.; Drendel, J. (dirs.): Les disettes dans la conjoncture de 1300 en Méditerranée occidentale. Roma, École française de Rome, 2011, pp. 343-416.

GHoutrgate, M., "La gestion des crises de subsistance par les souverains almohades" en Clément, F. (dir.): Histoire et nature: pour une histoire écologique des sociétés méditerranéennes. Rennes, Presses Universitaires, 2011, pp. 255-266.

Graham, N. E.; Ammann, C. M.; Fleitmann, D.; Cobb, K. M. y Luterbacher, J, "Support for global climate reorganization during the "Medieval Climate Anomaly", Climate Dynamics, Vol. 37/5-6 (2010), pp 1217-1245.

Goosse, H.; Renssen, H.; Timmermann, A. y Bradley, R. S., "Internal and forced climate variability during the last millennium: a model-data comparison using ensemble simulations". Quatern. Sci. Rev. 24 (2005), pp. 1345-1360.

Goosse, H.; Arzel, O.; Luterbacher, J.; Mann, M. E.; Renssen, H.; Riedwyl, N.; Timmermann, A.; Xoplaki, E. y Wanner, H., "The origin of the European "Medieval Warm Period". Climate of the Past, 2 (2006), pp. 99-113. 
Goosse, H.; Crespin, E.; Dubinkina, S.; Mann, M. E.; Renssen, H.; Sallaz-Damaz, Y. y SHINDELL, D., "The role of forcing and internal dynamics in explaining the "Medieval Climate Anomaly”. Climate Dynamics, 39 (2012), pp. 2847-2866.

Grove, J. M. y Switsur, R., "Glacial Geological Evidence for the Medieval Warm Period", Climatic Change 26 (1994), pp. 143-169.

GUICHARD, P., Al-Andalus frente a la conquista cristiana. Los musulmanes de Valencia (siglos XI - XIII), Valencia, Universidad de Valencia, 2001.

Guiot, J.; Corona, CH. and ESCARSEL members, "Growing season temperatures in Europe and climate forcings over the past 1400 years". PLoS ONE, 5-4 (2010), doi: 10.1371/journal. pone.0009972

Haug. G. H.; Günther, D.; Peterson, Th.; Sigman, D. M.; Hughen, K. A.; Aeschlimann, B., "Climate and the Collapse of Maya Civilization". Science, 299/5613 (2003), pp. 1731-1735.

Hughes, M. K. y Diaz, H. F., "Was there a 'Medieval Warm Period', and if so, where and when". Climatic Change, 26 (1994), pp. 109-142.

Huici Miranda, A., Historia politica del imperio almohade, I. Tetuán, Instituto de Estudios e Investigación Hispano-Árabe, 1947.

Hunt, B. G., "The Medieval Warm Period, the Little Ice Age and simulated climatic variability", Climate Dynamics, 27/7-8 (2006), pp 677-694.

INGSTAD, A. S., "The Excavation of a Norse Settlement at L'Anse aux Meadows, Newfoundland” en Ingstad, H. and Ingstad, A. S. (eds.): The Viking Discovery of America. New York: Checkmark, 2001, pp. 141-169.

Jones, P. D. y MANn, M. E., “Climate over past millennia”, Reviews of Geophysics, 42 (2004), doi: 10.1029/2003RG000143.

Julià Brugués, R. y RiERA Mora, S., "Usos del sòl i activitats productives a Barcelona a partir de l'anàlisi paleoambiental de la llacuna litoral medieval del pla del Palau". Quarhis: Quaderns d'Arqueologia i Història de la Ciutat de Barcelona, 6 (2010), pp. 164-177

KhaneBoubI, A., Les premiers sultans merinides: 1269-1331: histoire politique et sociale. París, L'Harmattan, 1987.

Kottek, M. Grieser, J.; Beck, Ch.; Rubel, F., "World Map of the Köppen - Geiger climate classification updated”. Meteorologische Zeitschrift, 15/3 (2006), pp. 259-263.

LALIENA CorberA, C., "Licencias para la exportación de cereal de Aragón y Cataluña a mediados del siglo XIII". Aragón en la Edad Media, 20 (2008), pp. 445-456.

LAmb, H., "The early Medieval warm epoch and its sequel". Palaeogeography, Palaeoclimatology, Palaeoecology, 1 (1965), pp. 13-37.

Lamb, H., Climate, History, and the Modern World. Londres, Taylor \& Francis, 1982.

LE Goff, J., "Bulletins météorologiques au XIIIe siècle" en Delort, R.; Mornet, E.; Morenzoni, F.: Milieux naturels, espaces sociaux: études offertes à Robert Delort. Paris, 1997, pp. 55-70.

Le Roy Ladurie, E., "Histoire et Climat." Annales É. S. C., 14/1 (1959), pp. 3-34.

Le Roy Ladurie, E., Histoire du climat depuis l'an Mil. Paris, Flamarion, 1983.

López-Días, V.; Borrego, Á. G.; Blanco, C. G.; Arboleya, M.; López SÁez, J. A. y López Merino, L., "Biomarkers in a peat deposit in Northern Spain (Huelga de Bayas, Asturias) as proxy for climate variation”. Journal of Chromatography, 1217 (2010), pp. 3538-3546.

López Sáez, J. A.; López Merino, L.; Pérez Díaz, S. y Mateo Mínguez, A., "Historia de la vegetación en el litoral norte de Girona entre los siglos VIII y XX d.c.: cambios climáticos y so- 
cioeconómicos desde una perspectiva paleoambiental", Arqueología y territorio medieval, 15 (2008), pp. 13-28.

López-SÁez, J. A., LóPez-Merino, L., Alba-Sánchez, F., PÉrez-DíAz, S., “Contribución paleoambiental al estudio de la trashumancia en el sector abulense de la Sierra de Gredos". Hispania, 69 (2009), pp. 9-38.

Mann, M. E. y Jones, PH. D., "Global surface temperatures over the past two millenia". Geophysical Research Letters, 30/15 (2003), 1820. doi:10.1029/2003GL017814

Mann, M. E.; Zhang, Z.; Hughes, M. K.; Bradley, R. S.; Rutherford, S. y Ni, F., "Proxy-based reconstructions of hemispheric and global surface temperature variations over the past two millennia". Proc. Natl. Acad. Sci. U. S. A. 105 (2008), pp. 13252-13257.

Mann, M. E.; Zhang, Z.; Rutherford, S.; Bradley, R. S.; Hughes, M. K.; Ammann, C.; Faluvegi, G., "Global Signatures and Dynamical Origins of the Little Ice Age and Medieval Climate Anomaly". Science 326/5957 (2009), pp. 1256-60.

Manrique, E. y FernáNDEZ-CANCIO, A., "Extreme climatic events in dendroclimatic reconstructions from Spain". Climatic Change, 44 (2000), pp. 123-138.

MAnZANo Martínez, J., "Aproximación a la estructura de la propiedad musulmana de la tierra en la Huerta de Murcia (siglo XIII)" en Castrum, 5. Madrid, Casa de Velázquez - Murcia, Ayuntamiento de Murcia, 1995, pp. 61-75.

Manzano MartíneZ, J., "Notas sobre demografía islámica en Murcia (siglos XII-XIII)". Miscelánea Medieval Murciana, XXV-XXVI (2001-2002), pp. 117-181.

Martín-Puertas, C.; Valero-Garcés, B. L.; Pilar Mata, M.; GonZalez-SAmpériz, P.; BaO, R.; Moreno, A. y Stefanova, V., "Arid and humid phases in southern Spain during the last 4000 years: the Zonar Lake record, Cordoba”, Holocene, 18 (2008), pp. 907-921.

Martínez EnAmorado, V., "Algunas reflexiones en torno al fin del almohadismo. El siglo XIII en el Islam de Occidente" en I Jornades de Recerca Històrica de Menorca. La Manürqa de Sa ‘ìd ibn Hakam, un país islàmic a Occident. Publicacions des Borns, 15-16 (2006), pp. 11-28.

Matthews, H. D.; Weaver, A. J.; Meissner, K. J.; Gillet, N. P. and Eby, M., "Natural and anthropogenic climate change: incorporating historical land cover change, vegetation dynamics and the global carbon cycle", Clim. Dyn., 22 (2004), pp. 461-479.

Menant, F., "Crisis de subsistencia y crisis agrarias en la Edad Media: algunas reflexiones previas" en Oliva Herrero, H. R. y Benito i Monclús, P. (eds.): Crisis de subsistencia y crisis agrarias en la Edad Media, Sevilla, Universidad de Sevilla, 2007, pp. 17-60.

Molina LóPEZ, E., “Aziz b. Jattab, destacada personalidad política, científica y literaria murciana del siglo XIII”. Miscelánea Medieval Murciana, IV (1978), pp. 63-86.

Molina LóPEz, E., "El Levante y Almería en el marco de la política interior del emir murciano Ibn Hûd al-Mutawakkil (1236 - 1238)". Awraq, 2 (1978), pp. 55-63.

Molina LóPEz, E., "Murcia en el marco histórico del segundo tercio del siglo XIII (1212-1258)" en Historia de la región murciana, III. Murcia, Ediciones Mediterráneo, 1980, pp. 187-263.

Molina LóPEz, E., "De nuevo sobre el reconocimiento público del poder político. La adhesión 'abbasí en al-Andalus (siglo XIII)" en Homenaje al Profesor José María Fórneas Besteiro, II, Granada, Universidad de Granada, 1994, pp. 793-812.

Morellón, M.; VAlero GArcés, B. L. y Rico, M., "Evolución sedimentaria y geoquímica del Lago de Estanyña (Huesca) durante los últimos 21.000 años”. Geogaceta, 46 (2009), pp. 115118. 
Moufti, M. R.; NÉMETH, K.; LINDSAY, J. M., “The 1256 AD al-Madinah historic eruption geosite as the youngest volcanic chain in the Kingdom of Saudi Arabia". International Journal of Earth Sciences, 102/4 (2013), pp.1069-1070.

Osborn, Th. J.; RAPER, SARAH C. B. y BrifFa, KeIth R., "Simulated climate change during the last 1,000 years: comparing the ECHO-G general circulation model with the MAGICC simple climate model". Climate Dynamics, 27 (2006), doi: 10.1007/s00382-006-0129-5

Palermo, L., "Carestie e cronisti nel Trecento: Roma e Firenze nel racconto dell'Anonimo e di Giovanni Villani”. Archivio Storico Italiano, 142 (1984), pp. 343-375.

Patterson, W. P.; Dietrich, K. A.; Andrews, J. T., “Two millennia of North Atlantic seasonality and implications for Norse colonies". Proceedings of the National Academy of Sciences, 107-12 (2010), pp. 5306-10.

Pérez Sanz, A.; González Sampériz, P.; Valero Garcés, B. L.; Moreno Caballud, A.; Morellón, M.; Sancho Marcén, C.; Belmonte Ribas, A.; Gil Romera, G.; Sevilla Callejo, M. y Navas IzQuierdo, A., "Clima y actividades humanas en la dinámica de la vegetación durante los últimos 2000 años en el Pirineo Central: el registro palinológico de la Basa de la Mora (Macizo de Cotiella)". Zubía, 23/Extra (2011), pp. 17-38.

Peterson, L. y Haug, G., "Climate and the Collapse of Maya Civilization". American Scientist, 93/4 (2005), pp. 322-329.

Pfister, Ch.; Lutterbacher, J.; Schwarz-Zanetti, G. y Wegmann, M., "Winter air temperature: variations in Central Europe during the Early and High Middle Ages (A.D. 750-1300)", The Holocene, 8 (1998), pp. 535-552

Reglero, C., "Les disettes dans le royaume de Castille (entre 1250 et 1348)" en Bourin, M.; Menant, F.; Drendel, J. (dir.): Les disettes dans la conjoncture de 1300 en Méditerranée occidentale. Roma, École française de Rome, (2011), pp. 309-342.

RiERA MELIS, A., "Els pròdroms de les crisis agràries de la Baixa Edat Mitjana a la Corona d'Aragó: 1250-1300". Miscel.lània en homenatge al P. Agustí Altisent. Tarragona, 1991, pp. 35-73.

RiERA Melis, A., "El mercado de los cereales en la corona catalanoaragonesa: la gestión de las carestías durante el segundo tercio del siglo XIII" en Bourin, M.; Menant, F.; Drendel, J. (dir.): Les disettes dans la conjoncture de 1300 en Méditerranée occidentale. Roma, École française de Rome, 2011, pp. 87-143.

Rовоск, A., "Volcanic eruptions and climate", Rev. Geophys., 38 (2000), pp. 191-219.

RodríGuez, A., "Foyse da terra no ano das chuvias... Carestías y subsistencia en el noroeste peninsular en los siglo XII y XIII” en Oliva Herrer, H. R. y Benito i Monclús, P. (eds.): Crisis de subsistencia y crisis agrarias en la Edad Media, Sevilla, Universidad de Sevilla, 2007, pp. 199-219.

RoDríGUEZ Llopis, M., "Repercusiones de la política alfonsí en el desarrollo de la región de Murcia" en Alfonso X. Aportaciones de un rey castellano a la construcción de Europa. Murcia, Editoria Regional, 1997, pp. 173-200.

SÁnchez de Valladolid, F., Crónica de Alfonso X en Villacañas Berlanga, J. L. (ed.), Murcia, Universidad de Murcia, 2005.

Schofield, PH. R., "Respuestas a la carestía y al hambre en el mundo rural inglés en los siglos XIII y XIV" en Oliva Herrero, H. R. y Benito i Monclús, P. (eds.), Crisis de subsistencia y crisis agrarias en la Edad Media, Sevilla, Universidad de Sevilla, 2007, pp. 229-243. 
Segura Graiño, C., "La tala como arma de guerra en la Frontera" en VI Estudios de Frontera. Población y poblamiento: Homenaje a Manuel González Jiménez. Jaén, Diputación Provincial, 2007, pp. 717-724.

SEgura Graiño, C., "Les recherches sur le climat dans la Couronne de Castille au Moyen Âge" en Clément, F. (dir.): Histoire et nature: pour une histoire écologique des sociétés méditerranéennes. Rennes, Presses Universitaires, 2011, pp. 147-162.

Soon, W. y Baliunas, S., "Proxy climatic and environmental changes of the past 1000 years", Climate Research, 23 (2003), pp. 89-110.

Stothers, R. B., "Climatic and demographic consequences of the massive volcanic eruption of 1258”. Climatic Change, 45 (2000), pp. 361-374.

Stothers, R. B. y RAmPino, M. R., "Historic Volcanism, European Dry Fogs, and Greenland Acid Precipitation, 1500 BC to AD 1500”. Science, 222 (1983), pp. 411-413.

Till, C. y Guiot, J., "Reconstruction of precipitation in Morocco since 1100 A. D. based on Cedrus atlantica tree-ring widths", Quaternary Research, 33 (1990), pp. 337-351.

Tiтow, J. Z., "Evidence of Weather in the Account Rolls of the Bishopric of Winchester, 12091350", The Economic History Review, 12 (1960), pp. 365-91.

Valero-Garcés, B. L.; González-Sampériz, L.; Navas, A.; Machín, J.; Mata, P.; DelgadoHuertas, A.; Bao, R.; Moreno, A.; Carrión, J. S.; Schwalb, A. y González-Barrios, A., "Human impact since Medieval times and recent ecological restoration in a Mediterranean lake: the laguna Zoñar (Spain)", Journal of Paleolimnology, 35 (2006), pp. 24-49.

VAQUero MartíneZ, J. M., "Reconstruction of Past Mediterranean Climate (700-1000 AD) using Arabic Chronicles: The Cases of Iberia, Syria and Iraq" en el symposium Climate Extremes During Recent Millennia and their Impact on Mediterranean Societies. Atenas, 1998.

Vaquero, J. M.; Gallego, M. C.; García-Herrera, R. y García, J. A., "Arabic Chronicles: an unexplored source for the reconstruction of past Mediterranean climate". First MedCLIVAR Workshop on Reconstruction of Past Mediterranean Climate Unexplored Sources of High Resolution Data in Historic Time. Sevilla, 2006.

VERNET, R., "Recherches sur la production et la circulation des céréales dans le Maghreb medieval", Revue d'Histoire et de Civilisation du Maghreb, 13 (1976), pp. 31-62.

VERNET, R., "La production cerealiere dans le maghreb du XIIIè Siecle" en X Congreso de Historia de la Corona de Aragón (vol. 3). Jaime I y su época, Zaragoza, Institución Fernando el Católico, 1982, pp. 253-268.

VIDAl CASTRO, F., “Al-Andalus y Marruecos en la Baja Edad Media (siglos XI-XV), una historia compartida y paralela". El zoco. Vida económica y artes tradicionales en al-Andalus y Marruecos. Granada, Fundación Legado Andalusí, 1995, pp. 11-47.

Viguera Molins, M. J., "Historia política" en Viguera Molins, M. J. (Coord.): El retroceso territorial de al-Andalus. Almorávides y almohades, Historia de España de Ramón. Menéndez Pidal (VIII-2), Madrid, Espasa-Calpe, 1997, pp. 100-123.

VV.AA., La Croissance agricole du Haut Moyen Âge. Chronologie, modalités, géographie. Dixièmes journées internationales d'histoire de Flaran, 9, 10, 11 septembre 1988. Auch, 1990. 